\title{
Multiscale modeling of bio-nano interactions of zero-valent silver nanoparticles.
}

\author{
Julia Subbotina, Vladimir Lobaskin \\ School of Physics, University College Dublin, Belfield, Dublin 4, Ireland
}

Keywords: silver nanoparticles, biocorona, interfaces, protein adsorption, coarse-grained modeling, multiscale modeling, biosensors, nanocarriers, nanotoxicity.

\begin{abstract}
Understanding the specifics of interaction between protein and nanomaterial is crucial for designing efficient, safe, and selective nanoplatforms, such as biosensor or nanocarrier systems. Routing experimental screening for the most suitable complementary pair of biomolecule and nanomaterial used in such nanoplatforms might be a resource-intensive task. While a variety of computational tools is available for pre-screening libraries of small drug molecules interacting with proteins, options for high-throughput screening of protein libraries for binding affinities to new and existing nanomaterials are limited. In the current work, we present the results of a systematic computational study of protein interaction with zero-valent silver nanoparticles using a multiscale approach. A variety of blood plasma and dietary proteins, namely, bovine and human serum albumins, bovine and human hemoglobin, papain, bromelain, lysozyme, and bovine
\end{abstract}


lactoferrin, were examined. Selected combinations of nanomaterial and proteins can serve as a starting model for developing noble metal-based nanocarriers and biosensors. The computed binding (adsorption) characteristics for selected proteins were validated by experimental data reported in the literature. An advanced in silico nano-QSAR/QSPR interfacial descriptor $\log P^{\mathrm{NM}}$ was also introduced to characterize the relative hydrophobicity/hydrophilicity of the nanomaterial.

\section{Introduction.}

The antimicrobial properties of metallic silver are well known for centuries ${ }^{1}$. During the last few decades, nanosilver found numerous applications in several fields ${ }^{2,3}$. In medicine ${ }^{4}$, it works as an antibacterial, antifungal, antiviral, or anti-inflammatory agent. It is also used as an antifouling coating on implants, catheters, and other surfaces contacting with biological fluids. These properties made nanosilver popular as an additive ingredient for textile and cosmetic products. Due to distinct and tunable plasmonic characteristics (specifically, a localized surface plasmon resonance), silver nanoparticles (AgNPs) attracted great interest for bio- and chemosensing applications $^{5-7}$. However, such popularity of AgNPs causing their increased occurrence in the biosphere raised many concerns due to a potential nanotoxicity ${ }^{8,9}$.

The potency of nanosized silver (where at least one dimension is less than $100 \mathrm{~nm}$ ) is linked to its higher reactivity arising from the higher surface-area-to-volume ratio when compared to the bulk material. After immersion of AgNPs into biological fluids (e.g. blood serum and plasma, mucus) they interact and form complexes with biomolecular solutes ${ }^{10}$. Depending on the exposure pathways (at the contact area of blood with medical instruments, air pathways, or skin), a multitude of biochemical and biophysical responses can be initiated ${ }^{11}$. One of the detected responses against a nanosized guest in the bloodstream is a formation of a protein corona, a layer(s) of blood plasma 
proteins on the surface of the nanomaterial ${ }^{12}$. That mask, built of proteins, gives a pristine NP "a new identity"13 which helps it to stay below the cellular defense radars and allows it to penetrate the cell membrane. After passing into the cell, the NP can interact with other cell constituents at all levels of the cell organization, from organelles to lipid bilayer/proteins/DNA to individual biomolecules (e.g. carbohydrates, amino acids (AA), cholesterol, etc.). These interactions occurring at the bio-nano interface provide the background for the toxicity of NPs. Although nanotoxicity itself is an undesirable consequence of the exposure of a living organism to the nanosized material, it can be harnessed to provide benefits in fighting enemies, e.g. cancer cells or pathogenic bacteria. The ability of NPs to slip through the cell defensive barrier makes them attractive candidates for developing drug delivery and detecting platforms, aiming for hard-to-treat cancers, neurodegenerative, and other types of human diseases ${ }^{14}$.

A decoration of NPs with a specific protein targeting extracellular membrane elements of the tumor cell (e.g. CD markers ${ }^{15,16}$ ) directs the NP toward the localization area of the cells. After the attachment, the NP can damage the membrane of the tumor cell causing its death. Alternatively, an NP loaded with a drug can act as a nanocarrier ${ }^{17,18}$, delivering antitumor reagent directly to the target (Figure 1). Coupling of the NP to the protein that is complementary to a membrane receptor can occur either via chemical bonding or physisorption. In some cases, physical adsorption of specific proteins may result in a higher efficacy of nanocarriers due to improved cell uptake ${ }^{19}$. 
Figure 1. Working principle of drug nano-carrier for cancer therapies.

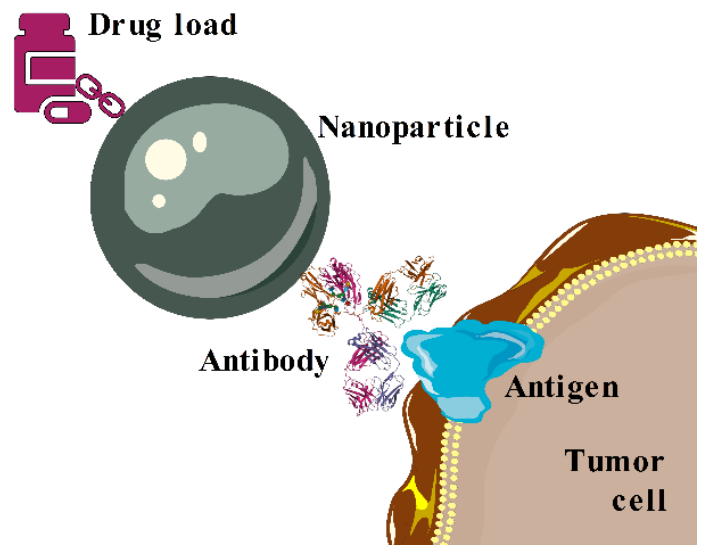

Caption: The figure was prepared by using Servier Medical $\mathrm{Art}^{20}$ service.

Finding an optimal protein-NP combination for a drug nanocarrier model experimentally can be a challenging task, as it relies on the systematical screening of large libraries of proteins and NPs. Alternatively, the pre-screening for potential candidates can be performed in silico. Numerous computational approaches have been developed to evaluate the relevant binding affinities with the help of rigorous protocols combining docking techniques and molecular dynamics simulations ${ }^{21-}$ 23. Yet, despite their accuracy and veracity, brute-force techniques are hardly applicable for screening multiple protein adsorbates due to their significant computational costs. A typical computation of the protein adsorption energy using an all-atom model entails using enhanced sampling technics, to address the vast number of degrees of freedom of the protein, which can undergo relatively large conformational changes in globular structure upon adsorption onto a solid surface. Given the size of the system such as a protein-NP complex and the high energy barriers associated with this interaction ${ }^{24-28}$, getting a representative sampling becomes a profound task. To overcome the dimensionality problem, several coarse-grained (CG) models of bio-nano interactions have been introduced. In particular, we proposed a bottom-up multiscale approach to estimate adsorption energies ${ }^{29-31}$. In this method, a globular protein is represented by a one-bead- 
per-amino-acid CG rigid structure (a UnitedAtom (UA) scheme). The total interaction potential between the protein and NP is obtained by summing up all the molecular interactions between the protein segments and the NP. The total energy of interaction between the nanomaterial and adsorbed protein in the $U A$ model is evaluated as a sum of a short-range contribution computed with a high resolution using an all-atom MD and a long-range contribution evaluated via a CG potential. The UnitedAtom model has been already applied to predict protein binding energies for titania and gold $\mathrm{NPs}^{32,33}$.

In the current work, we extend the application of the $U A$ method for predicting protein adsorption affinities to zero-valent silver NPs. We present the short-range surface interaction potentials between three FCC facets of AgNP and thirty-two biomolecular fragments (amino acid, carbohydrate, and lipid fragments) sufficient to create CG UA models of different proteins (including glyco-, and lipoproteins). Obtained short-range surface interaction potentials are then utilized and validated for the prediction of the adsorption characteristics for several blood plasma proteins and food proteins by the UnitedAtom model.

\section{Methods and materials.}

The UnitedAtom Model. In this section, we present the main theory for the UnitedAtom model $^{29-}$

${ }^{31}$. In the $U A$ model, only physical adsorption of biomolecules on nanomaterial surfaces is considered. It is assumed that both entities are in an aqueous medium containing counterions or salts with constant concentration. The water is represented implicitly. The protein is represented as a rigid body with CG beads, that is, no internal movement is accounted for within the protein. In the simplest approximation of the $U A$ model, the nanoparticle is also treated as a rigid flat surface, sphere, or cylinder with a defined thickness/radii. 
The total interaction potential between NP and the protein for a given configuration is written in a pairwise-additive way via individual non-bonded interaction potentials for each CG AA bead, which depend on the distance $d_{i}$ between centers of mass (COM) of NP and the AA bead. The distance $d_{i}$, in turn, depends on the orientation of the whole protein with respect to the NP surface, which is defined by two rotational angles $\theta$ and $\phi$ relative to the initial protein orientation defined in the PDB file:

$U_{P-N P}=\sum_{i=1}^{N_{A A}} U_{i}^{A A-N P}\left(d_{i}(\theta, \phi)\right)$

The CG interaction energy for each AA is a sum of non-bonded (van der Waals, dipolar, and excluded volume) and electrostatic terms:

$U_{i}^{A A-N P}\left(d_{i}(\theta, \phi)\right)=U_{i}^{\mathrm{el}}\left(d_{i}(\theta, \phi)\right)+U_{i}^{n b}\left(d_{i}(\theta, \phi)\right)$

The electrostatic interaction potential between NP and AA, which implicitly accounts for properties of the environment, e.g. ionic strength $I$, buffer composition, and salts concentrations $c_{i}$, the dielectric constant of solvent $\epsilon$, is defined as follows:

$U_{i}^{\mathrm{el}}\left(d_{i}(\theta, \phi)\right)=\frac{\varphi_{s} q_{i} R_{N P}}{R_{N P}+h_{i}\left(d_{i}, \theta, \phi\right)} e^{-\kappa h_{i}\left(d_{i}, \theta, \phi\right)}$

where $\varphi_{s}$ is the electrostatic surface potential of NP, $R_{N P}$ is NP radius, $h_{i}\left(d_{i}, \theta, \phi\right)$ is a distance between the center of mass for AA and the surface of the nanoparticle, $\kappa=\lambda_{D}^{-1}=\sqrt{8 \pi l_{B} I}$ is the inverse Debye length, $l_{B}=\frac{e_{0}^{2}}{4 \pi \epsilon \epsilon_{0} k_{B} T}$ is the Bjerrum length, and $I$ is the ionic strength of the background electrolyte:

$I=\frac{1}{2} \sum_{i} c_{i} z_{i}^{2}$

The $\mathrm{pH}$ of the medium is excluded from consideration in this work as we assume a neutral $\mathrm{pH}$ in all calculations. 
Although the NP is assumed to be homogeneous in the $U A$ model, nonbonded interactions of AA with the NP's inner core and surface parts are modeled at different resolutions. The non-bonded potential is split into two parts, representing the non-bonded interaction of each AA with the NP surface and its core. It depends on the distance between NP surface and the COM for amino acid:

$U_{i}^{\mathrm{nb}}\left(h_{i}\left(d_{i}, \theta, \phi\right)\right)=U_{i, s}^{\mathrm{nb}}\left(h_{i}\left(d_{i}, \theta, \phi\right)\right)+U_{i, c}^{\mathrm{nb}}\left(h_{i}\left(d_{i}, \theta, \phi\right)\right)$

The boundary between the core and the surface regions of NP is defined by a cut-off distance $r_{c}$ (Figure 2) and any non-bonded interactions below that distance (short-range surface potential $\left.U_{i, s}^{\mathrm{nb}}\left(h_{i}\left(d_{i}, \theta, \phi\right)\right)\right)$ are calculated by all-atom MD simulations. Typical values for $r_{c}$ are in the range 1.0-1.2 nm, and the choice depends on the selection of force field for calculations of the short-range surface potential.

Figure 2. Definition of cut-off distance for the Hamaker potential in $U A$ model (lens model ${ }^{29}$ ).

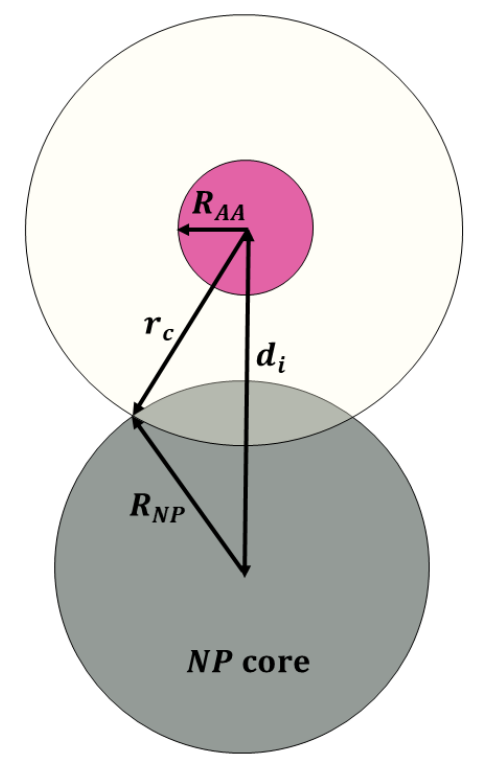

Non-bonded interactions outside the cut-off distance (long-range core potential $U_{i, c}^{\mathrm{nb}}$ ), arising from dispersion forces acting through the water medium between NP's core and the $i$-th AA of radius $R_{A A}$, are approximated by Hamaker potential ${ }^{34}$ : 
$U_{i, c}^{n b}\left(R_{N P}, R_{A A}, d_{i}(\theta, \phi)>r_{c}\right)=-\frac{A_{132}}{12}\left(\frac{4 R_{N P} R_{A A}}{d_{i}(\theta, \phi)^{2}-\left(R_{N P}+R_{A A}\right)^{2}}+\frac{4 R_{N P} R_{A A}}{d_{i}(\theta, \phi)^{2}-\left(R_{N P}-R_{A A}\right)^{2}}+\right.$

$\left.2 \ln \left(\frac{d_{i}(\theta, \phi)^{2}-\left(R_{N P}-R_{A A}\right)^{2}}{d_{i}(\theta, \phi)^{2}-\left(R_{N P}+R_{A A}\right)^{2}}\right)\right)$

where $A_{132}$, is a Hamaker constant for materials 1 (nanomaterial) and 2 ( $i$-th $\left.\mathrm{AA}\right)$ interacting through the solvent 3 . It can be calculated ${ }^{34}$ from experimentally measured dielectric permittivity $\epsilon_{j}$ and the refractive index $n_{j}$ of participating phases $j=1,2,3$ :

(a) If materials 1 (AA) and 2 (NP) are both dielectric ones:

$$
A_{132} \approx \frac{3 k_{B} T}{4}\left(\frac{\epsilon_{2}-\epsilon_{3}}{\epsilon_{2}+\epsilon_{3}}\right)\left(\frac{\epsilon_{1}-\epsilon_{3}}{\epsilon_{1}+\epsilon_{3}}\right)+\frac{3 h v_{2}}{8 \sqrt{2}} \frac{\left(n_{1}^{2}-n_{3}^{2}\right)\left(n_{2}^{2}-n_{3}^{2}\right)}{\sqrt{\left(n_{1}^{2}+n_{3}^{2}\right)} \sqrt{\left(n_{2}^{2}+n_{3}^{2}\right)}\left(\sqrt{\left(n_{1}^{2}+n_{3}^{2}\right)}+\sqrt{\left(n_{2}^{2}+n_{3}^{2}\right)}\right)}
$$

(b) If nanomaterial 2 is piezoelectric/conducting/semiconducting:

$$
A_{132} \approx \frac{3 h}{8 \sqrt{2}} \frac{\left(n_{1}^{2}-n_{3}^{2}\right)}{\left(n_{1}^{2}+n_{3}^{2}\right)} \frac{v_{2} \sqrt{v_{1} v_{3}}}{\sqrt{v_{1} v_{3}}+\frac{v_{2}}{\sqrt{n_{1}^{2}-n_{3}^{2}}}}
$$

where $v_{i}$ is an electronic absorption frequency at maximum absorbance peak in UV spectra of corresponding dielectric materials; for the conducting material $v_{i}$ is a plasma frequency ( e.g. $v_{2}$ in eq. 8).

At distances shorter than $r_{c}$, the short-range core potential $U_{i, c}^{\mathrm{nb}}\left(h_{i}\left(d_{i}, \theta, \phi\right)\right)$ should be corrected to avoid double counting of the non-bonded interactions encoded in the potential mean force (PMF) along the surface separation distance (SSD) ${ }^{35}$ computed by atomistic MD simulations:

$$
\begin{aligned}
& U_{i, c}^{n b}\left(R_{N P}, R_{A A}, d_{i}(\theta, \phi)<r_{C}\right)=\frac{A_{132}}{12}\left(\frac { 4 \pi ^ { 2 } R _ { A A } ^ { 3 } } { 3 d _ { i } ( \theta , \phi ) } \left(\frac{d_{i}(\theta, \phi)-3 R_{N P}}{\left(d_{i}(\theta, \phi)-R_{N P}\right)^{3}}+\right.\right. \\
& \left.\left.\frac{-6 r_{c}^{2}+8 r_{c} d_{i}(\theta, \phi)-3 h\left(d_{i}(\theta, \phi)+R_{N P}\right)}{r_{c}^{4}}\right)\right)
\end{aligned}
$$

The final summation of all terms described above over all the AAs yields the interaction energy for a given $\left(\theta_{k}, \phi_{l}\right)$ orientation of the whole protein located at a given $z$-distance between COM 
of NP and COM of the protein. Sampling over all possible protein orientations defined by rotational angles $\left(\theta_{k}, \phi_{l}\right)$ at all $z$-distances produces a set of $U_{P-N P}\left(z, \theta_{k}, \phi_{l}\right)$ potentials corresponding to a multitude of configurations for an NP-protein complex. The mean interaction energy for a particular orientation $\left(\theta_{k}, \phi_{l}\right)$ within a corresponding distance interval $0 \leq z \leq$ $a\left(\theta_{k}, \phi_{l}\right)$ can be evaluated as:

- for the protein interacting with a flat slab:

$E\left(\theta_{k}, \phi_{l}\right)=-k_{B} T \ln \left(\frac{1}{a\left(\theta_{k}, \phi_{l}\right)} \int_{0}^{a\left(\theta_{k}, \phi_{l}\right)} \exp \left[\frac{-U_{p-N P}\left(z, \theta_{k}, \phi_{l}\right)}{k_{B} T}\right] d z\right)$

- for the protein interacting with a spherical NP:

$E\left(\theta_{k}, \phi_{l}\right)=-k_{B} T \ln \left(\frac{3}{\left(R_{N P}+a\left(\theta_{k}, \phi_{l}\right)\right)^{3}-R_{N P}^{3}} \int_{R_{N P}}^{R_{N P}+a\left(\theta_{k}, \phi_{l}\right)} \exp \left[\frac{-U_{p-N P}\left(z, \theta_{k}, \phi_{l}\right)}{k_{B} T}\right] z^{2} d z\right)$

Averaging the mean interaction energies $E\left(\theta_{k}, \phi_{l}\right)$ over all possible configurations $\left(\theta_{k}, \phi_{l}\right)$ yields the final mean adsorption energy $E_{a d s}^{A}$ (arithmetic mean of the values obtained at all the sampled protein orientations) $)^{36}$. Alternatively, an average adsorption energy $E_{a d s}^{B}$ is evaluated via canonical averaging with Boltzmann weighting factors $P_{k l}$ :

$E_{\text {ads }}^{B}=\frac{\sum_{k} \sum_{l} P_{k l} E\left(\theta_{k}, \phi_{l}\right)}{\sum_{k} \sum_{l} P_{k l}}$

$P_{k l}=\sin \left(\theta_{k}\right) \exp \left[-\frac{E\left(\theta_{k}, \phi_{l}\right)}{k_{B} T}\right]$

Reconstruction of a short-range NP-AA surface potential $U_{i, s}^{\mathrm{nb}}\left(h_{i}\left(d_{i}, \theta, \phi\right)\right)$ from the potential of mean force. Various techniques exist for an accurate evaluation of the binding free energy for molecules ${ }^{37-40}$. Recently, an adaptive well-tempered metadynamics ${ }^{41}$ has become popular to obtain the free energy of interaction as it provides accurate energy estimates based on an enhanced sampling of configurational space at a reasonable computational cost. The application of this method to study interfacial systems was previously described in Ref. ${ }^{35}$ for the adsorption of biomolecules on the $\mathrm{TiO}_{2}(100)$ surface. The reported protocol was closely followed in the 
current work with some adjustments related to the use of a different force field. All MD simulations in the present work were performed in GROMACS ${ }^{42}$.

Three different FCC configurations of a silver slab $(100,110,111)$ were constructed by CHARMM-GUI/Nanomaterial Modeler ${ }^{43}$ tool. The slab thickness for each configuration varied from 1.012 to $1.180 \mathrm{~nm}$. The simulation boxes for PMF runs were constructed in the following way: the biomolecule fragment was placed above the silver slab $1.5 \mathrm{~nm}$ away from the surface, the system was solvated by TIP3P water and neutralized by $0.15 \mathrm{KCl}$. The final dimensions of starting simulation boxes were approximately $2.4 \mathrm{~nm} \times 2.4 \mathrm{~nm} \times 8.5 \mathrm{~nm}$.

The simulation systems were subject to two subsequent preliminary unbiased equilibrations for 30 ns each under NPT and NVT ensemble conditions. The temperature was kept constant at $300 \mathrm{~K}$. The ambient pressure was set at 1 bar. The relaxation time constant for the Nose-Hoover thermostat for the NVT ensemble was 5 ps, while Berendsen's weak coupling thermostat and barostat were invoked for NPT simulations. Periodic boundary conditions were invoked for all MD simulations.

Pre-equilibrated systems underwent biased adaptive well-tempered metadynamics simulations under NVT conditions for at least 600 ns to obtain an adequate sampling yielding PMF profiles. The AWT-metadynamics simulations were performed by GROMACS ${ }^{42}$ coupled with PLUMED ${ }^{44}$ software. The collective variable (CV) $h_{i}$ for one-dimensional adsorption PMFs, the surface separation distance (SSD), was defined as in work ${ }^{35}$ and was sampled in a range between 0.0 and $2.0 \mathrm{~nm}$. The temperature for biased simulations was set at $300 \mathrm{~K}$. Gaussian hills were added every 0.5 ps starting with an initial height of $2.5 \mathrm{~kJ} / \mathrm{mol}$. The bias factor was $f=20$. 
Particle Mesh Ewald (PME) scheme was used for long-range electrostatics treatment in all simulations. The recommended ${ }^{42}$ for CHARMM force field parameters cut-off distance $(1.2 \mathrm{~nm})$ was used for treating for short-range van der Waals interactions and long-range electrostatics.

The convergence of AWT-metadynamics runs was controlled via the evolution of three parameters during the simulation: (1) the collective variable SSD, (2) the heights of hills, and (3) the free energy difference between minimum located on PMFs and the global minimum (the lowest state). The Metadynminer R package ${ }^{45}$ was utilized for this purpose.

Nanomaterial hydrophobicity descriptor as a function of the heat of immersion. To understand the driving forces behind biomolecular adsorption onto inorganic nanomaterials it is instructive to quantify the adsorbent's interaction with the solvent. The enthalpy of wetting (often presented as the heat of immersion) is the enthalpy change associated with immersing a solid in a wetting liquid, and it can be considered as a measure of hydrophobicity/hydrophilicity of the nanomaterial. The enthalpy of immersion can be measured experimentally by calorimetry or predicted computationally. A convenient computational method ${ }^{46}$ includes an estimation of enthalpy difference between three systems: solid slab immersed in a liquid, the same solid in a vacuum, a box of the same number of molecules of liquid as in the slab-liquid system. The immersion enthalpy then can be calculated as:

$\Delta H_{\text {imm }}=\frac{1}{2 A}\left(H_{\text {slab-liquid }}-H_{\text {liquid }}-H_{\text {slab }}\right)$,

where $A$ is the area of the interface in the slab-liquid system.

When characterizing a nanomaterial for biomedical applications (e.g. implant or dental filling biocompatibility), it is essential to understand the relative affinity of the material to physiological aqueous liquids vs. lipid bilayer. In vHTS/QSAR studies on draggability of the small molecules, the comparative hydrophobicity/lipophilicity of a compound is usually described via the octanol- 
water partitioning coefficient $\log P^{47,48}$, which is a logarithm of the ratio between solute (drug) concentrations in a biphasic system of $n$-octanol and water, and can be evaluated computationally via an alchemical thermodynamic cycle based on relevant solvation free energies ${ }^{49,50}$ :

$\log P=\log \left(\frac{[\text { solute }]_{\text {octanol }}}{[\text { solute }]_{\text {water }}}\right)=\frac{\Delta G_{\text {water }}-\Delta G_{\text {octanol }}}{R T \ln (10)}$

Based on this idea, we propose to quantify relative hydrophilicity/hydrophobicity of a solid crystalline nanomaterial as a function of relative enthalpy of immersion of a well-defined periodic NP slab in water and octanol, representing physiological aqueous and lipid phases:

$\log P^{N M}=\frac{\Delta H_{i m m}^{\text {water }}-\Delta H_{\text {imm }}^{\text {octanol }}}{R T} \log (e)$

This interfacial descriptor can be useful for predicting cell adhesion properties of materials, known to correlate with biocompatibility. A negative value of $\log P^{N M}$ indicates that the material will have a higher affinity for the aqueous phases (hydrophilic), while a positive one should be indicative of the material with an affinity to hydrophobic (e.g. protein corona) and lipophilic (e.g. cell membrane) environments. The $\log P^{N M}$ descriptor does not include entropic terms corresponding to structural reorganization in slab/biphasic systems which may occur upon mutual interaction. Thus, althouth this approach has certain limitations in characterizing hydrophobicity/lipophilicity of nanomaterials, it should be useful for comparative nanoinformatics studies.

To obtain the $\Delta H_{\text {imm }}$ values for all FCC configurations of silver, the corresponding systems (NP slab, octanol and water boxes, NP slab in water and octanol) were pre-equilibrated for $30 \mathrm{~ns}$ and simulated further for $350 \mathrm{~ns}$ under NPT conditions to ensure proper statistics for collected energies. All other parameters for these runs were similar to those in biased simulations. The energy files corresponding to collected trajectories were analyzed to obtain enthalpy averages and error estimates using block averaging (gmx energy and gmx analyze modules). 


\section{Selection of force field parameters for MD simulations of processes occurring at the bio-nano}

interface. Various force fields, polarizable and non-polarizable, were proposed to model noble metal nanoparticles and their interactions with biomolecules. ${ }^{51-56}$ In the current work, the nonpolarizable INTERFACE force field by Heinz et al. ${ }^{54,57}$ was used for the metallic "nano" part of the system, while CHARMM36 force field parameters ${ }^{58}$ were invoked for the remaining "bio" part. Inclusion of polarization effects implicitly via rigorous parametrization in additive INTERFACE/CHARMM36 FFs may result in some inconsistencies when they are applied to model the bio-nano interface phenomena ${ }^{59}$. The use of polarizable FFs might be more beneficial. Yet, not many existing polarizable force fields cover a large number of inorganic materials and biomolecules and are suitable for consistent parametrization of further materials with the UnitedAtom method. In principle, accurate treatment of the image charge interactions at the metal interface can be achieved by a posteriori inclusion of the polarization effects ${ }^{60}$, although at a significant computational cost. For our current study, the exclusion of polarizable effects for calculation of short-range potentials for adsorption of single AA did not substantially impact the outcome - the relative adsorption affinities ranking of proteins (protein abundancies) calculated by the multiscale $U A$ approach, especially for the proteins with a low net charge.

The CHARMM36 FF topology files for AAs were adapted to simulate only the side-chain fragment: atoms in the backbone group in corresponding AAs were replaced by a neutrally charged hydrogen atom (Figure 3). The short-range potential for GLY amino acid was not calculated. Instead, it was replaced by silver - ALA potential for UA calculations. INTERFACE FF and CHARMM topology and parameters files then were converted to GROMACS format with the TopoTools ${ }^{61}$ plugin in VMD. 
Three-dimensional structures for proteins. The structures of proteins studied in this work were obtained from Protein Data Bank (PDB) and prepared for further modeling by CHARMMGUI/PDB Reader ${ }^{62}$. No additional structural refinement by molecular dynamics was done. The protein was considered a "rigid body". As we have shown ${ }^{32}$ previously, an RMSD change in position of $\mathrm{C}_{\alpha}$ atoms of $\mathrm{AA}$ residue up to $0.1 \mathrm{~nm}$ does not alter the mean binding energy for protein significantly. Although, because the protein can undergo a partial unfolding upon binding to the $\mathrm{NP}$, representing the protein as a set of rigid structures with perturbed coordinates might be more accurate where the strong unfolding of protein is observed. Proteins selected for the current study were characterized with a moderate structural change associated with binding to the silver surface, without losing their biological functions. And thus, a single protein structure with coordinates preserved from the PDB file was utilized for calculations of binding energy. The protonation state of the proteins was the one corresponding to the neutral $\mathrm{pH}$. 
Figure 3. Sidechain analogs of amino acids, carbohydrates, and lipid fragments.

Sidechains of amino acids

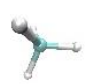

ALA

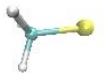

CYM

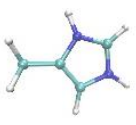

HSP

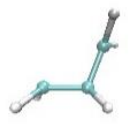

PRO

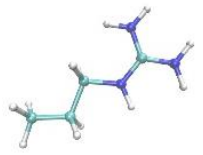

ARG

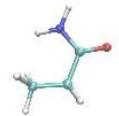

GLN

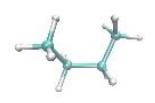

ILE

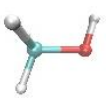

SER

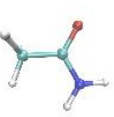

ASN

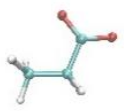

GLU

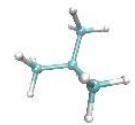

LEU

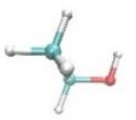

THR

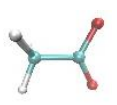

ASP

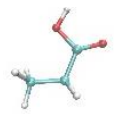

GLUP

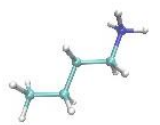

LYS

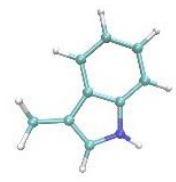

TRP

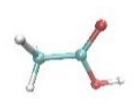

ASPP

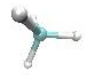

GLY

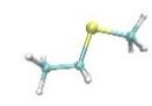

MET

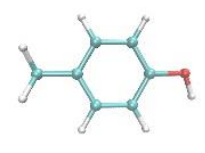

TYR

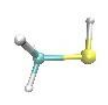

CYS

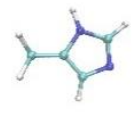

HSE/HSD

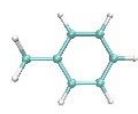

PHE

\section{Lipid fragments}

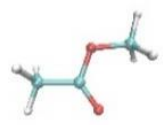

MAS (methylacetate)

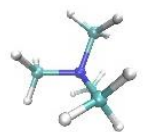

NC4

(tetramethylammonium)

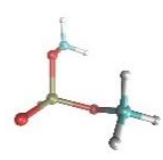

DMEP

(dimethylphosphate)

\section{Carbohydrates}

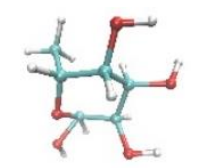

AFUC

( $\alpha$-L-fucose)

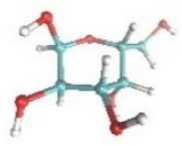

AMAN

( $\alpha$-D-mannose)

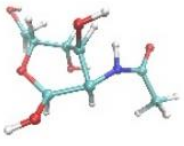

BGLCNA

(2-acetyl-2deoxy- $\beta$-Dglucosamine)

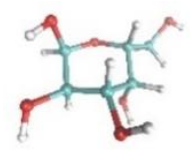

BGLC

( $\beta$-D-glucose)

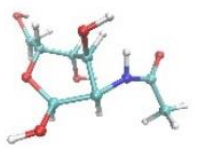

BGALNA

(2-acetyl-2deoxy- $\beta-D$ galactosamine) 


\section{Results.}

\section{Short-range surface adsorption potentials of carbohydrates, lipid fragments, and amino acid}

side chains. In total, 96 PMF profiles for adsorption of biomolecules were calculated to reconstruct the short-range surface potential, $U_{i, s}^{\mathrm{nb}}\left(h_{i}\left(d_{i}, \theta, \phi\right)\right)$ for three metallic silver faces (Figure 4 and Figures S1a,b in Supporting material). The majority of PMFs converged within 400 ns of production run (the example of convergence criteria for $\operatorname{Arg}-\operatorname{Ag}(110)$ system is shown in Figures S2a-c, in Supporting material). However, larger molecules required slightly longer simulation (up to $600 \mathrm{~ns}$ ) to obtain reasonable configurational sampling.

Values of adsorption energy $\Delta F_{\text {ads, }}$ calculated by numerical integration of PMF curves, are collected in Table S1 in Supporting material. In general, biomolecules prefer to be adsorbed onto (111) or (110) facets of AgNPs: the calculated mean values of adsorption energy $\Delta F_{a d s}$ per SCA were $-1.94 k_{B} T,-5.83 k_{B} T$, and $-6.03 k_{B} T$ for $\operatorname{Ag}(100), \operatorname{Ag}(110)$, and $\operatorname{Ag}(111)$ slabs, respectively. Aromatic residues were predicted to bind stronger to all silver surfaces as compared to aliphatic SCAs (Figure 5). This trend was particularly evident for $\operatorname{Ag}(111)$ surface. The preference of aromatic molecules to be bound to (111) noble metal surfaces were previously explained ${ }^{57}$ by the better match between atoms of the hexagonal ring and epitaxial sites on the metallic plane. A strong interaction between $\mathrm{Au}(111)$ epitaxial sites and polarizable atoms $(\mathrm{O}, \mathrm{N}, \mathrm{C})$ resulted in soft epitaxial adsorption.

The general binding prevalence of aromatic AAs was also observed experimentally for the interaction of various di- and three-peptides with colloidal silver ${ }^{63}$, where Phe, Tyr, and Trp sites demonstrated a stronger adsorption affinity. The authors in this work ruled out the $\pi$-bonding as a driving force for adsorption of Tyr and Phe residues and noted a high affinity of the amino group for the silver surface which resulted in peptides' adsorption via N-terminus. This binding pattern 
was explained by the attraction between two polarizable dipoles, associated with an electron density of AgNP outer layer on one side, and a delocalized $\pi$-system on aromatic rings or a charged terminus on the other side ${ }^{64,65}$.

A binding preference for linear molecules for (110) surfaces was reported ${ }^{57}$ and explained by better geometric alignment of polarizable atoms with epitaxial sites on an inorganic surface. Calculated binding energies for SCA support this observation: Lys was predicted to bind stronger to $\operatorname{Ag}(110)$ surface than Phe SCA. Arginine and methionine aliphatic residues were calculated to be common strong binders for all three facets (Figure 5).

At the same time, heteroatom-rich biomolecules, such as carbohydrates and dimethyl phosphate, were also predicted to have a strong interaction with AgNP: N-acetyl hexosamines (eg. BGALNA) and carbohydrates (eg. AMAN) were the strongest adsorption determinants among all biomolecules considered in the current study. The mean adsorption free energy $\Delta F_{\text {ads }}$ for this molecular class was calculated at $-9.35 k_{B} T,-15.12 k_{B} T$, and $-19.86 k_{B} T$ for $\operatorname{Ag}(100), \operatorname{Ag}(110)$, and $\operatorname{Ag}(111)$ crystal planes (Table S1, Supporting material).

Predicted strong binding of carbohydrates to the silver surface can be related to antimicrobial potency of colloidal silver ${ }^{66}$, as sugars are important in maintaining the integrity of viruses and bacteria by supporting their membrane functions. In viruses, glycans are located on their outer surface and responsible for the attachment of the virus to the cell membrane of the infected host ${ }^{67}$. Thus, trapping glycans by AgNP should counteract host-virus association. For bacteria, the interaction of colloidal silver with peptidoglycans, composing bacterial cell walls, should also impact bacterial functions ${ }^{68}$, as glycans play a crucial role in cellular pathways present in microbes. 

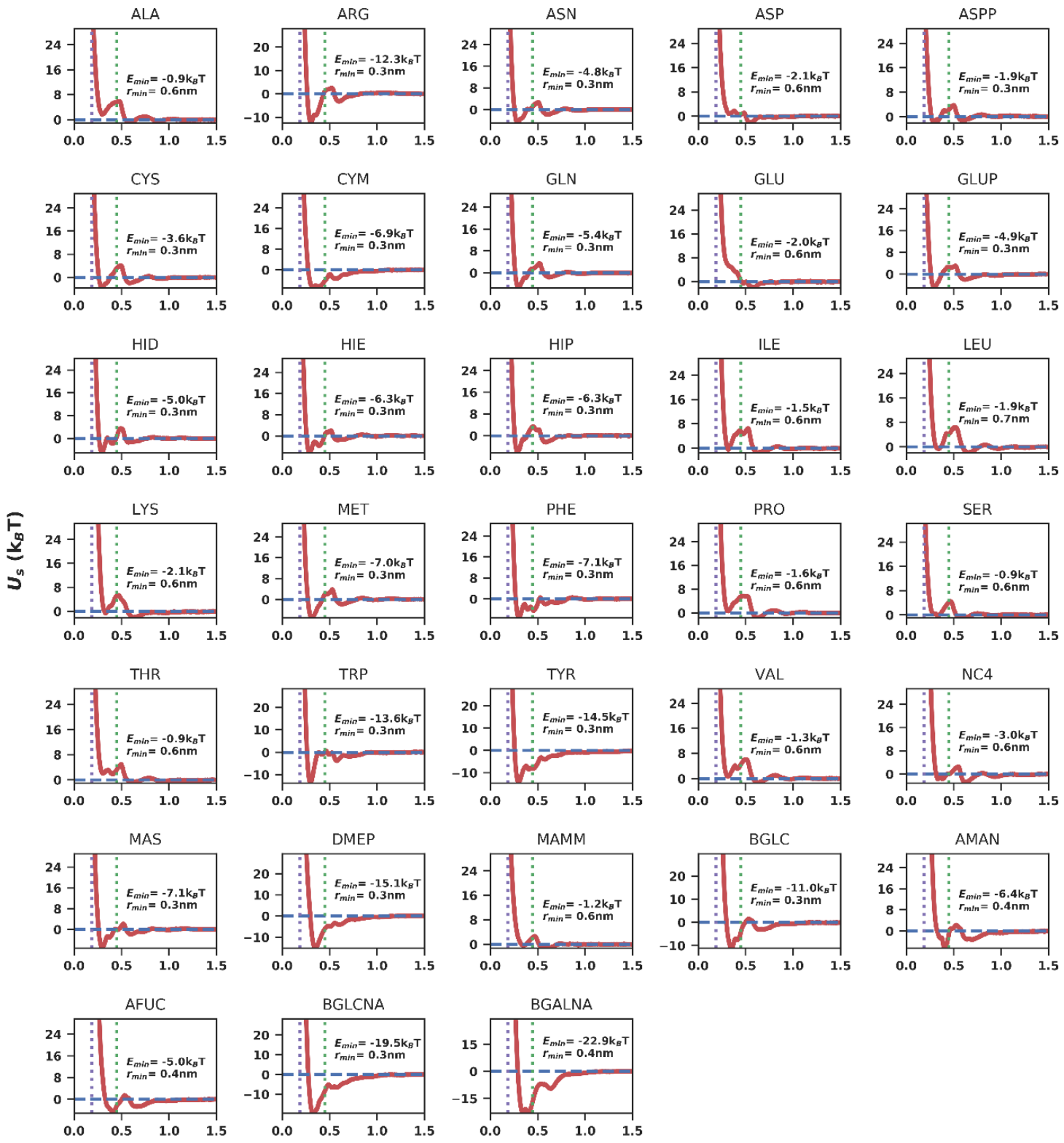

SSD (nm)

Figure 4. Short-range surface adsorption potential profiles for $\operatorname{Ag}(100)$ surface as a function of the surface separation distance (SSD) for carbohydrates, lipid fragments, and SCAs.

The profiles were obtained with adaptive well-tempered metadynamics (AWT-MetaD) simulations. $E_{\min }-$ the energy of the lowest minimum. Magenta and green vertical dashed lines show the positions of maxima of the density profile for the first and the second water shells around the AgNP. 

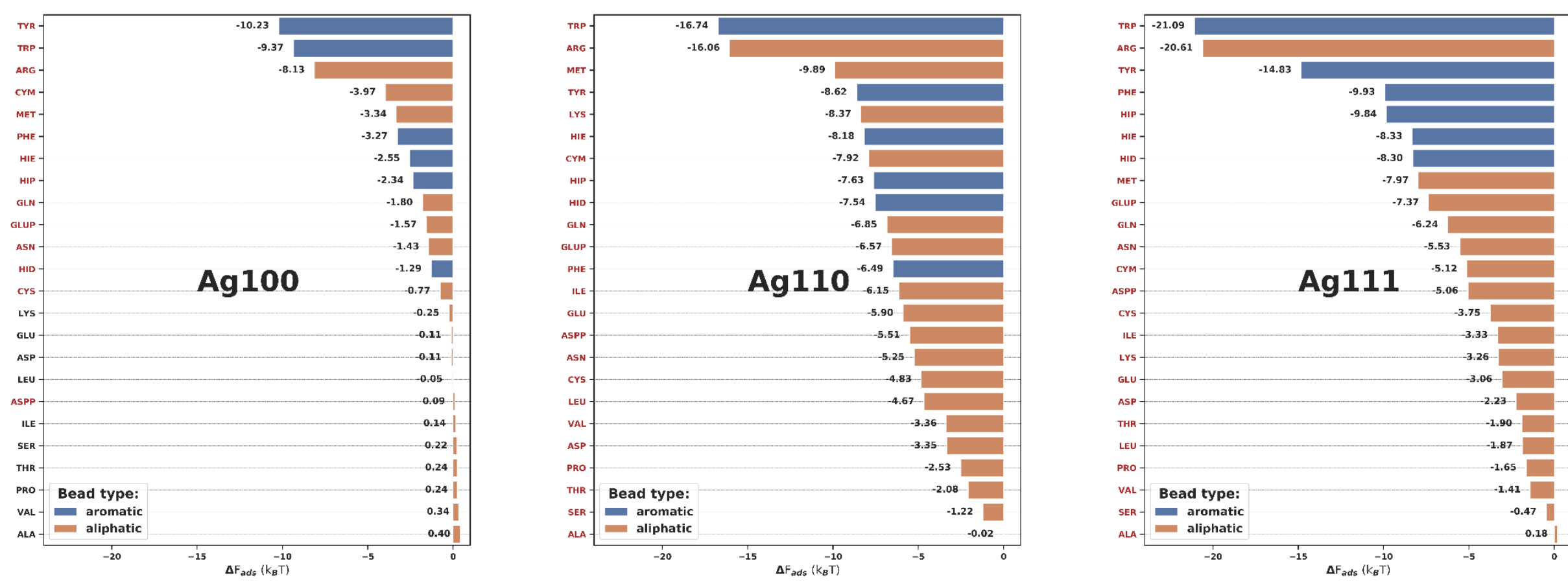

Figure 5. Adsorption energies for biomolecules $\Delta F_{a d s}$ as calculated by numerical integration of PMF curves.

Caption: Aromatic SCA (in blue) has a slight preference for adsorption onto silver surfaces. The distinct preference for aromatic SCA was predicted for $\operatorname{Ag}(111)$ surface. On average, SCAs have a preference to bind $\operatorname{Ag}(110)$ facet, followed by $\operatorname{Ag}(111) \operatorname{and} \operatorname{Ag}(100)$.

SCAs names highlighted in red color (left axis) can permeate through the second water shell around AgNPs. The least binding preference for $\operatorname{Ag}(100)$ facet correlates with the inability of the majority of SCA to permeate through the second water layer. 


\section{The structured hydration shell around silver nanoparticles and hydrophobicity of}

nanomaterial. The shape of computed PMFs for SCAs was impacted by the character of interfacial interaction occurring between the NP with the solvent. The water density profiles for the interfacial water layer obtained from MD simulations of the "slab-water" system suggest the existence of two regions with elevated water density found $0.15-0.20 \mathrm{~nm}$ and $0.45-0.49 \mathrm{~nm}$ away from the silver surface. Two permeable water regions were located at $0.26-0.27 \mathrm{~nm}$ and $0.55-0.68$ $\mathrm{nm}$. Analysis of MD trajectories shows that water molecules in the first structured layer have the direction of their dipole moments aligned with the positive direction of the normal to the metal surface, as the cosine of the angle between these two vectors remains positive (Figures S4a-f in Supporting material) at approx. $0.25 \mathrm{~nm}$ and $0.6 \mathrm{~nm}$ (so the angle is $-90^{\circ} \leq \beta \leq 90^{\circ}$ ). Such orientation of water dipoles is in line with existing experimental data on a solvent organization for various colloidal $\mathrm{NPs}^{69}$. The presence of two layers, weakly linked to AgNP, at an interfacial hydration shell was confirmed experimentally by Raman spectroscopy ${ }^{70}$. Authors have shown, that water molecules surround almost spherical silver particles and have their hydrogen atoms revolved towards the metal surface.

Computed PMF profiles (shown in Figure 4 and Figures S1a,b in Supporting material) had no adsorption minima next to the NP surface (SSD $<0.15 \mathrm{~nm}$ ), suggesting that adsorbates were not able to expel water molecules from the first hydration shell around AgNP. Although, they were able to penetrate through the second interfacial water layer. The adsorption of protonated Asp residue onto $\operatorname{Ag}(110)$ surface was the only exception, as two equal minima were located before and after the position of the first hydration shell.

In the case of the $\operatorname{Ag}(100)$ surface, an additional adsorption minimum appeared at ca. 0.5-0.6 $\mathrm{nm}$, suggesting that biomolecules may also remain in the bulk of the solvent without passing 
through the second hydration layer (Figure 4). This behavior resulted in the weaker binding of biomolecules to $\operatorname{Ag}(100)$ surface (Figure 5) and can be linked to the higher hydrophilicity of $\operatorname{Ag}(100)$ surface, as compared to $\operatorname{Ag}(110)$ and $\operatorname{Ag}(111)$ surfaces.

Various quantities have been used in literature to characterize engineered nanoparticles by their hydrophilicity/hydrophobicity ${ }^{71-73}$, e.g. contact angles, surface free energies, the heat of immersion $^{74}$, or octanol-water affinity coefficients $(\mathrm{KAOw})$. Nonetheless, their applicability for the characterization of a large dataset of engineered materials can be a daunting task not only due to time-consuming analytical technics but also due to the inconsistency of measured results (e.g. surface energies for $\mathrm{AgNPs}^{75}$ ). In silico tools predicting those characteristics are available, but also susceptible to the same issues. For example, inconsistent estimates for the surface free energies for silver slabs in vacuum obtained at a different level of DFT approximation have been published ${ }^{76-}$ ${ }^{78}$ (Table 1).

We used MD simulations with Eq. 14 to evaluate the immersion enthalpies for three silver surfaces as described above. The calculated immersion enthalpies for silver slabs (Table 1) indicate a slightly more hydrophilic character of the $\operatorname{Ag}(100)$ facet as compared to $\operatorname{Ag}(110)$ or $\operatorname{Ag}(111)$. Thus, hydrophobic molecules (e.g. proteins) will be less likely to replace water molecules from the water shells of the $\operatorname{Ag}(100)$ surface, and they will rather adsorb on (110) or (111) facets. At the same time, the immersion enthalpies calculated for "slab-octanol" systems point out a stronger interaction of AgNPs with hydrophobic/lipophilic matter, rather than with aqueous environments $\left(\log P^{N M}>0\right)$. 
Table 1. Surface descriptors of hydrophobicity/hydrophilicity for FCC Ag.

\begin{tabular}{|l|l|l|l|}
\hline \multicolumn{1}{|c|}{ Surface descriptors } & \multicolumn{1}{|c|}{$\operatorname{Ag(100)}$} & \multicolumn{1}{|c|}{$\operatorname{Ag(110)}$} & \multicolumn{1}{|c|}{$(\mathbf{1 1 1})$} \\
\hline Surface Energy* $\left(\mathrm{J} / \mathrm{m}^{2}\right)^{76}$ & 1.290 & 1.420 & 1.140 \\
\hline Surface Energy* $\left(\mathrm{J} / \mathrm{m}^{2}\right)^{77}$ & 0.820 & 0.870 & 0.760 \\
\hline Surface Energy* $\left(\mathrm{J} / \mathrm{m}^{2}\right)^{78}$ & 1.206 & 1.057 & 0.881 \\
\hline Immersion enthalpy** in pure water $\left(\mathrm{kJ} / \mathrm{mol} \mathrm{nm}^{2}\right)$ & $-276.70 \pm 1.0$ & $-206.7 \pm 0.5$ & $-204.6 \pm 0.5$ \\
\hline Immersion enthalpy** in octanol $\left(\mathrm{kJ} / \mathrm{mol} \mathrm{nm}^{2}\right)$ & $-287.0 \pm 3.0$ & $-289.0 \pm 5.0$ & $-308.0 \pm 5.0$ \\
\hline $\log P^{N M * * *}$ & 6.04 & 14.49 & 18.13 \\
\hline
\end{tabular}

*Previously reported computed values of surface energies. Surface energy can serve as a measure of hydrophobicity. The lower the surface energy, the stronger the surface repels the water.

**Immersion enthalpies computed in the current work. The lower the enthalpy, the higher the preference for the material to be wetted with the selected solvent. The immersion enthalpy in water provides the measure of hydrophobicity/hydrophilicity. The immersion enthalpy in octanol provides estimates of lipophilicity.

***Relative measure of hydrophobicity/lipophilicity.

Multiscale CG modeling of protein adsorption on a silver nanoparticle. Thermodynamics and kinetics of protein adsorption process onto pristine AgNP have been previously addressed for various blood plasma, milk, and other dietary proteins ${ }^{79,80,89,90,81-88}$ : e.g. bovine (BSA, PDBID: 3V03) and human (HSA, PDBID:1AO6) serum albumins, bovine (BHb, PDBID: 1FSX) and human (HHb, PDBID: 1GZX) hemoglobin, papain (PDBID: 9PAP), bromelain (PDBID:1W0Q), lysozyme (PDBID: 1AKI), and bovine lactoferrin (BLf, PDBID:1BLF). Reported experimental metrics for listed proteins were used to assess the predictive power of the $U A$ method. The adsorption of all proteins was reported to be exothermic, associated with negative free Gibbs 
energy values (Table 2). According to the circular dichroism (CD) spectra, these proteins experience relatively small changes in globular structure upon interaction with AgNPs: observed loss of $\alpha$-helical content was $\sim 3-10 \%{ }^{83,84,87-91}$. Based on that, the "rigid body" approximation applied in the $U A$ scheme should not cause a significant error in adsorption energy estimates, arising from inaccurate information on protein coordinates.

Table 2. Experimentally measured free energy of adsorption $\Delta G_{a d s}$ vs. calculated $E_{a d s}$ for selected proteins.

\begin{tabular}{|c|c|c|c|c|c|c|}
\hline \multirow{2}{*}{ PDB ID } & \multirow{2}{*}{$\begin{array}{c}\text { Total charge, } \\
\text { e }\end{array}$} & \multirow{2}{*}{$\begin{array}{c}\text { R(NP), } \\
\text { nm }\end{array}$} & \multirow{2}{*}{$\begin{array}{c}\zeta \text {-potential, } \\
\mathrm{mV}\end{array}$} & \multirow{2}{*}{$\begin{array}{l}\Delta \mathbf{G}_{\text {ads }}, \\
\mathrm{kJ} / \mathrm{mol}\end{array}$} & \multicolumn{2}{|c|}{ Eads, $\mathrm{kJ} / \mathrm{mol}$} \\
\hline & & & & & $\mathbf{E}_{\mathrm{ads}}^{\mathbf{A}}$ & $\mathbf{E}_{\text {ads }}^{\mathbf{B}}$ \\
\hline $1 \mathrm{BLF}^{90}$ & 13 & 18.0 & -28.1 & -81.59 & -34.47 & -275.63 \\
\hline $1 \mathrm{~W} 0 \mathrm{Q}^{85}$ & 5 & 40.0 & $-6.0^{92}$ & -72.85 & -27.61 & -204.78 \\
\hline $9 \mathrm{PAP}^{85}$ & 9 & 40.0 & $-6.0^{92}$ & -59.76 & -37.40 & -213.71 \\
\hline $3 \mathrm{~V} 03^{91}$ & -32 & 40.0 & $-6.0^{92}$ & -39.49 & -30.89 & -175.01 \\
\hline $1 \mathrm{AKI}^{86}$ & 8 & 40.0 & $-6.0^{92}$ & -28.71 & -32.33 & -169.79 \\
\hline $1 \mathrm{AO}^{87}$ & -30 & 43.0 & $-6.0^{92}$ & -22.14 & -27.87 & -154.70 \\
\hline $1 F S X^{84}$ & 2 & 10.0 & $-12.5^{93}$ & -19.10 & -23.54 & -111.46 \\
\hline $1^{G_{Z X X}}{ }^{83}$ & 2 & 15.0 & -15.5 & -14.43 & -24.54 & -112.36 \\
\hline
\end{tabular}

The experimental parameters for NP sizes and $\zeta$-potentials were invoked in the $U A$ scheme to calculate average adsorption energies $\left(E_{a d s}^{A}\right.$ and $E_{a d s}^{B}$ ), and to predict the lowest energy configurations of adsorption complexes. The inconsistency in reporting experimental parameters of NPs for protein adsorption experiments should be specially mentioned ${ }^{94}$. For example, no information was available for $\zeta$-potential of 40-43 nm-sized AgNPs used in studies ${ }^{85-87,91}$. For 
these instances, the $\zeta$-potential reported ${ }^{92}$ for the $40-70 \mathrm{~nm}$ distribution of spherical AgNPs synthesized in presence of poly( $N$-vinylpyrrolidone) (PVP), was used $(-6 \mathrm{mV})$. Although the polymeric capping should alter the $\zeta$-potential of pristine NPs, the authors of the study suggested, that impact of the PVP layer on particles' properties should be minimal. Similarly, no $\zeta$-potential was reported in the study of $\mathrm{BHb}$ adsorption ${ }^{84}$. For this case, measured value ${ }^{93}$ for $4-12 \mathrm{~nm}$ distribution of biosynthesized AgNPs was applied (-12.5 mV).

AgNPs used in experiments exhibit various types of crystal facets (see Supporting Material). Assuming that all facets equally contribute to protein adsorption, the final values for predicted absorption energies $E_{a d s}^{A}$ and $E_{a d s}^{B}$ were calculated as an arithmetic mean over the three facets (100), (110), (111) (Table 2).

The resulting heatmaps for protein adsorption onto three facets of AgNPs are shown in Figure S5 in Supporting Materials. The calculated adsorption footprint of the same proteins on the metallic NP facets remains similar, with minor differences corresponding to the appearance/disappearance of alternative orientations of the protein. Even though the values of mean adsorption energy per single amino acid calculated from PMF profiles were almost equal for (110) and (111) facets ($5.83 k_{B} T$ vs. $\left.-6.03 k_{B} T\right)$, a distinct preference for $\mathrm{Ag}(110)$ binding emerged, as a result of cooperative binding of amino acids composing protein (Table S2).

Proteins containing glycosylated amino acids in their structure, e.g. bromelain and bovine lactoferrin, were predicted to be the strongest interfacial adsorbates (Table 2), yet the contact between the NP surface and these proteins occurred through the charged residues, rather than carbohydrate fragments (Supporting Material, cases 6 and 8). Positively and negatively charged residues (Arg, Lys, Glu, Asp) were the most frequent contact fragments in protein complexes with $\mathrm{NM}$, found in the proximity $(0.3-0.4 \mathrm{~nm})$ of metallic silver (Figure 6). On the contrary, aromatic 
residues, e.g. Trp and Thr, did not make direct contact with Ag atoms. This forecast does not contradict the experimental data from synchronous fluorescent spectrometry (SFS) for protein adsorption which suggested the change of microenvironment for aromatic residues upon protein adsorption in the case of BSA, HSA, bromelain, papain, lysozyme, and lactoferrin. A slightly different behavior has been shown for hemoglobins in the SFS experiment, as tryptophane was observed to act as a binding site (see Supporting Materials, cases 3 and 4). However, it should be noted that the change of microenvironment occurring near aromatic residues observed in SFS experiments can be also linked to protein adsorption in its partially unfolded state. Thus, future developments of the $U A$ model are required to improve the current resolution level for a description of protein adsorption. A detailed report on predicted structures for metal-protein adsorption complexes and on their alignment with available experimental data can be found in the Supporting Materials, Cases 1-8. 
Figure 6. Lowest energy conformations of adsorption complexes at $\operatorname{Ag}(110)$ surface for selected proteins:

BSA (a), HSA (b), BHb (c), HHb (d), bromelain (e), papain (f), lysozyme (g), and BLf (h).

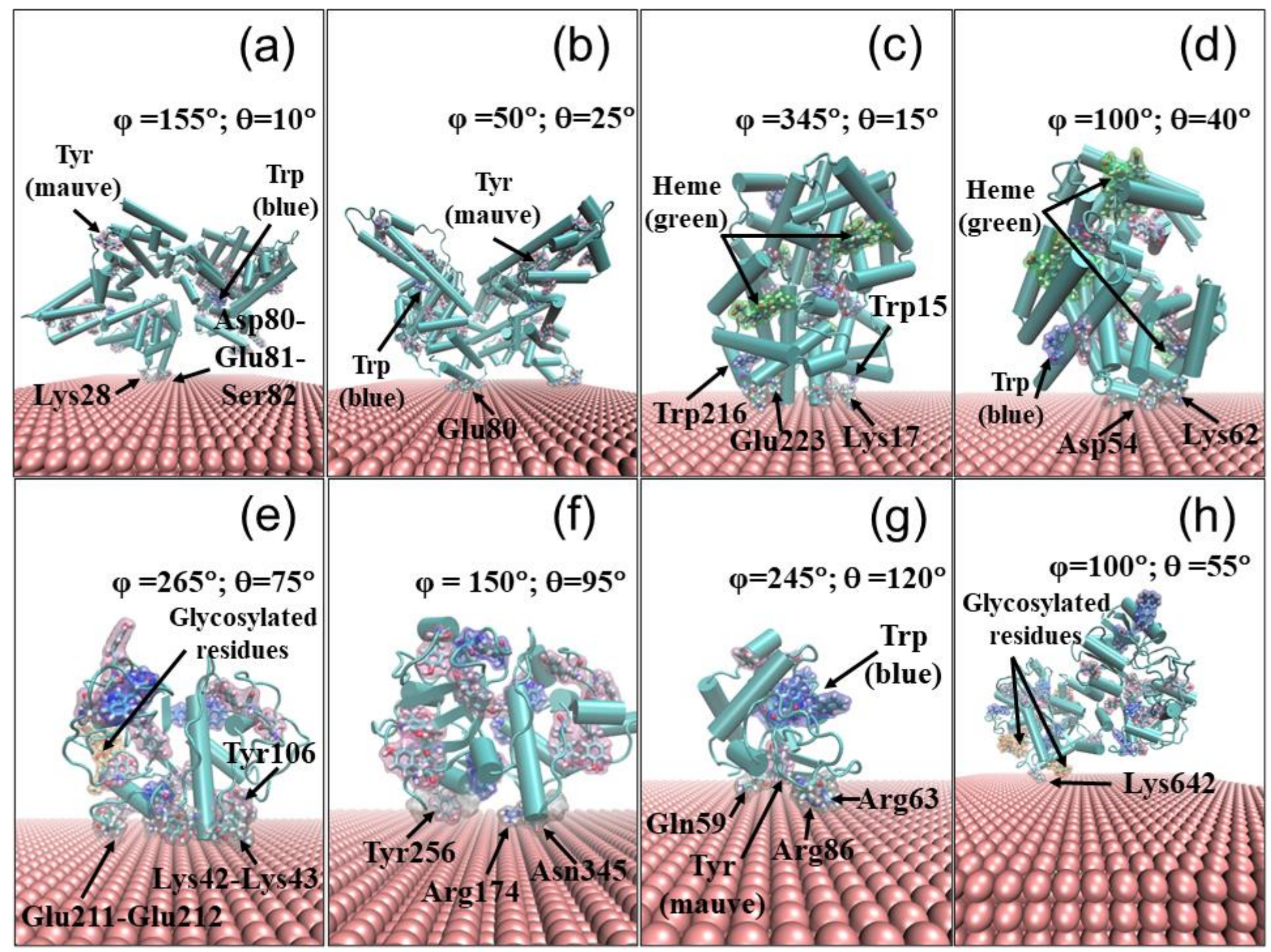




\section{Discussion}

Adsorption of proteins on metallic surfaces is a complex phenomenon that proceeds through several common stages ${ }^{95}$ : (1) protein diffusion from the bulk of solvent to the interface, (2) protein anchoring to the second surface-bound water layer, (3) protein conformational rearrangement ${ }^{96}$ to achieve a better position and orientation within the second layer until (4) a lockdown state is reached, and final (5) protein self-diffusion at the water/solid interface to complete the adsorption. Modeling the details of such processes at the atomistic level for large proteins is currently unfeasible, so one needs multiscale approaches involving coarse-graining of the bio-nano interface. In addition, one can attempt a data-driven approach for predicting such interaction, where large sets of data are available. To describe properly the interaction of biomolecules with inorganic materials, nanoQSAR models should include descriptors for proteins, nanomaterials, and descriptors corresponding to processes occurring at the solid/liquid interface (interfacial descriptors). Protein adsorption energies and quantitative measures of hydrophobicity/hydrophilicity, e.g. enthalpies of wetting, can serve as interfacial descriptors for nanoQSAR models and in principle can be estimated computationally through molecular dynamics and multiscale simulations. However, some considerations should be taken into account.

For example, as existing force fields usually do not provide a full set of parameters for many inorganic materials ${ }^{59}$, the calculated values of wetting enthalpies for different materials obtained from different force fields cannot be compared directly. As a result, the hydrophilicity/hydrophobicity ranking of nanomaterials based on these values might be inconsistent. In this scenario, the relative measure of hydrophilicity/hydrophobicity calculated within the same force field, such as $\log P^{N M}$ can perform better as an interfacial descriptor for the 
nanoQSAR models providing the comparison between a range of nanomaterials $\mathrm{x}$ (e.g. prediction of cell adhesion responses for different NPs).

Computed values for the energy of adsorption $E_{\text {ads, }}$, either via the canonical averaging or simple averaging, showed an adsorption ranking similar to one predicted experimentally (Table 2). It should be noted that the exact mapping between $\Delta G_{a d s}$ and the energy of adsorption $E_{\text {ads }}$ is not possible for several reasons. First of all, the rigid body approximation of protein ${ }^{29-31}$ implemented in the UnitedAtom model does not include energy terms related to structural rearrangements occurring at the bio-nano interface during the adsorption process (e.g. protein unfolding). However, for proteins exhibiting insignificant changes in the globular structure upon adsorption, these increments are expected to be small. The structure of interfacial water does also undergoes changes associated with cavity formation and protein insertion ${ }^{97}$ which takes place during the experiment. Solvent reorganization effects related to the changes associated with a whole protein structure cannot be directly captured by the UnitedAtom approach as a result of rigid body approximation and the implicit description of the solvent. Yet, these effects are partially included for individual side chains in the short-range surface potential $U_{i, s}^{\mathrm{nb}}\left(h_{i}\left(d_{i}, \theta, \phi\right)\right)$ obtained via explicit all-atoms MD simulations.

The implicit modeling of the environmental factors (e.g. variation in ionic strength and $\mathrm{pH}$ ) for the bio-nano interface may also lead to inaccurate estimates for electrostatic interactions between proteins and charges surfaces ${ }^{98}$ occurring at experimental conditions. Additional errors can be also inflicted by the neglect of image charge interactions between the charged residues and metallic surfaces existing in the current formulation of the United Atom model. The missing polarization energy contribution can be recovered either by using polarizable force fields at the atomistic MD level during the calculation of the $\mathrm{PMFs}^{60}$ or later at the $\mathrm{CG}$ level modeling by 
invoking a mean-field Poisson-Boltzmann theory ${ }^{99}$. Based on the obtained results, the overall effect of not including these increments was relatively small as there were no large discrepancies between predicted and observed adsorption affinity rankings for highly negatively charged proteins (e.g. 3V03 and 1AO6, see Table 2).

It is also important to note that the $U A$ method may overestimate the protein adsorption energies, as it includes the contributions from optimized arrangements of individual SCAs at the surface. However, in a real protein, where the translations and rotations of the side chains are constrained, not all arrangements of SCAs at the metal surface are reachable. This can explain the relatively high values of adsorption energies, obtained by the ensemble averaging scheme $\left(E_{\text {ads }}^{B}\right)$ where all configurations of NP-protein adsorption complex are included (eq. 12). At the same time, the NP coatings commonly present in experiments as dispersion stabilizers may significantly reduce the observed adsorption energies, as the layer of ligands is usually less dense than the bulk silver and it increases the distance between the residues and the AgNP surface ${ }^{100}$. The attractive Van der Waals terms in the overall interaction energy are very short-ranged, and thus, are extremely sensitive to such changes in distances.

Despite all the mentioned limitations of the UnitedAtom approach, we found a good statistical correlation between experimental $\Delta G_{a d s}$ and predicted ensemble-averaged $E_{a d s}^{B}$ values: the calculated correlation coefficient was $r=0.93$ ( $\mathrm{p}<0.005$, Figure 7). A weaker, statistically less relevant correlation $(r=0.62, \mathrm{p}>0.005)$ was calculated for $E_{a d s}^{A}$ values. As a result, we propose that the $E_{a d s}$, calculated with the canonical Boltzmann average approximation $\left(E_{a d s}^{B}\right)$ can serve as a better interfacial descriptor for nanoQSAR models. Although, further investigations are required to validate the statistical performance of this descriptor with a larger dataset of proteins (e.g. by predicting corona composition). 
Figure 7. Correlation between the experimentally measured free energy of adsorption $\Delta G_{a d s}$ and $E_{a d s}$ predicted by the $U A$ method.
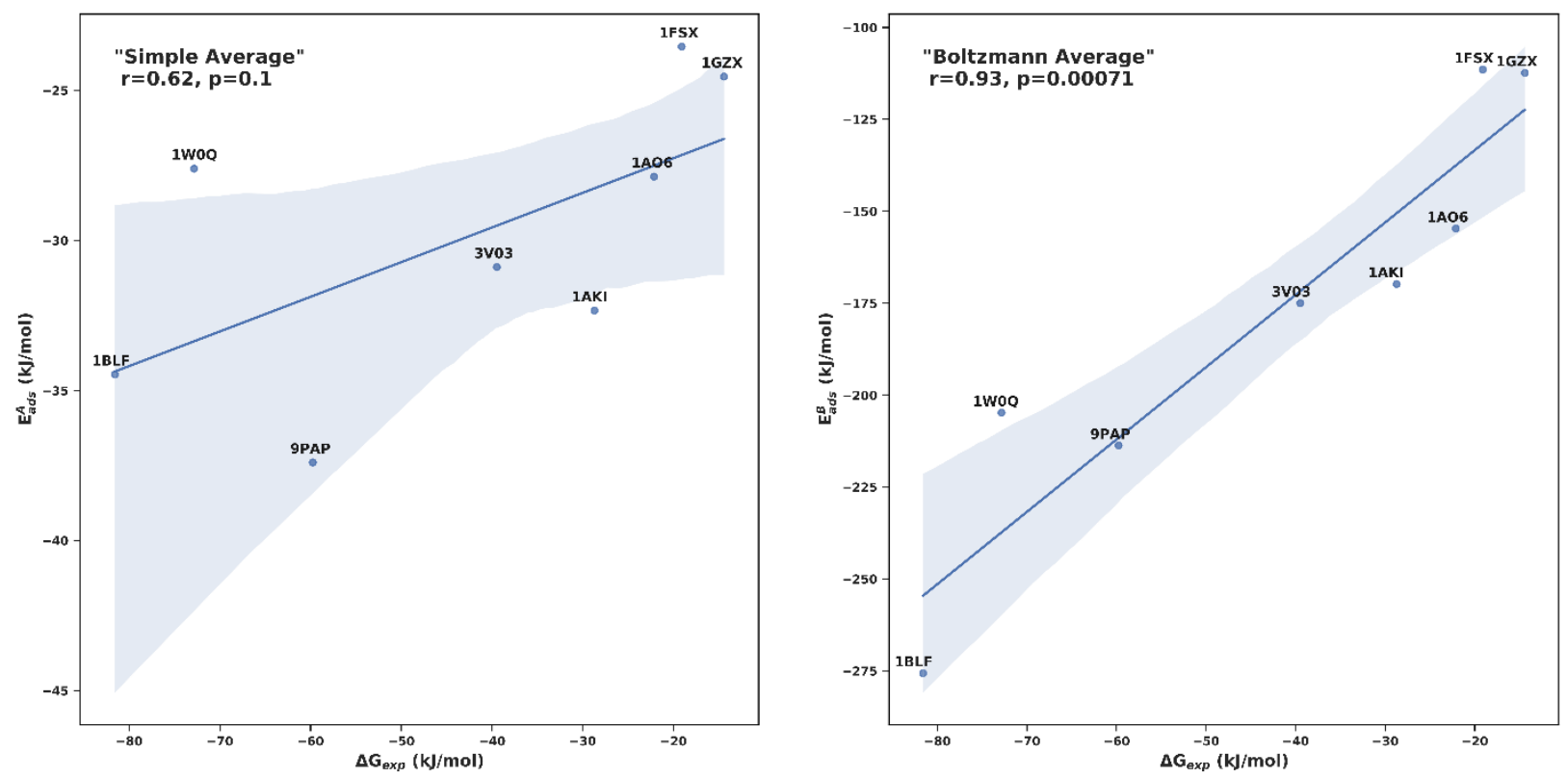

Previously, it was also proposed to use the adsorption affinity ranking ${ }^{32}$ as a predictive interfacial descriptor of protein adsorption for in silico protein corona composition predictions instead of $E_{a d s}$. For the present set of proteins, a very good match between experimental and calculated adsorption affinity ranking was observed for values obtained with the ensemble average (Table 3 ). The correct predicted ranking may be the main advantage of the $U A$ approach, as it allows us to model the NP's biological activity via NanoQSARs ${ }^{101}$. It has been previously demonstrated, that the statistics of the NP protein corona (e.g. weighted relative counts of AA types in the adsorbed proteins) can be quantitatively related to the association of gold or silver NPs with cells ${ }^{102}$. A relative abundance of the proteins in the corona for a specific material reflects the importance of different contributions to the adsorption energy and should be less sensitive to the absolute values of energy, but more sensitive to the affinity ranking. 
Experimental adsorption energy ranking for selected proteins suggests that glycoproteins (bromelain and bovine lactoferrin) have the highest affinity toward AgNPs. A similar trend for glycoproteins is also confirmed by affinity ranking obtained by the ensemble average $U A$ approximation. In line with this trend, our calculations have shown that glycosylation should improve overall adsorption on AgNPs, yet the direct contact with the surface is not necessarily maintained through the carbohydrate moiety (Figure 6e,h).

Table 3. Comparison of binding affinity ranking obtained by two averaging approximations for adsorption of proteins onto silver NP ordered by the binding strength.

\begin{tabular}{|l|l|l|l|}
\hline Ranking & Experimental & $\begin{array}{c}\text { Simple average } \\
\text { approximation }\end{array}$ & $\begin{array}{c}\text { Canonical average } \\
\text { approximation }\end{array}$ \\
\hline 1 & $1 \mathrm{BLF}$ & $9 \mathrm{PAP}$ & $1 \mathrm{BLF}$ \\
\hline 2 & $1 \mathrm{~W} 0 \mathrm{Q}$ & $1 \mathrm{BLF}$ & $9 \mathrm{PAP}$ \\
\hline 3 & $9 \mathrm{PAP}$ & $1 \mathrm{AKI}$ & $1 \mathrm{~W} 0 \mathrm{Q}$ \\
\hline 4 & $3 \mathrm{~V} 03$ & $3 \mathrm{~V} 03$ & $3 \mathrm{~V} 03$ \\
\hline 5 & $1 \mathrm{AKI}$ & $1 \mathrm{AO} 6$ & $1 \mathrm{AKI}$ \\
\hline 6 & $1 \mathrm{AO} 6$ & $1 \mathrm{~W} 0 \mathrm{Q}$ & $1 \mathrm{AO} 6$ \\
\hline 7 & $1 \mathrm{FSX}$ & $1 \mathrm{GZX}$ & $1 \mathrm{GZX}$ \\
\hline 8 & $1 \mathrm{GZX}$ & $1 \mathrm{FSX}$ & $1 \mathrm{FSX}$ \\
\hline
\end{tabular}

\section{Conclusions.}

In this work, we presented the results of multiscale modeling of adsorption of biomolecules on zero-valent AgNPs using the all-atom MD and the UnitedAtom algorithm. The low computational 
cost of the $U A$ method for predicting protein adsorption energies makes this approach relevant for high-throughput in silico probing for binding affinities of various proteins (including glycoproteins and lipoproteins) to inorganic nanomaterials. The $U A$ method can be applied for computational pre-screening of biomolecules in the development of bioassays and drug nanocarriers, for predicting NP protein corona composition, or for evaluation of nanotoxicity. The method provides not only the energy of adsorption, calculated as a function of NP size, shape, and $\zeta$-potential, but it is also capable of predicting the specific three-dimensional structure of NP-protein complexes (nano-docking). The current distribution of the software ${ }^{103}$ is parameterized to predict the energy of physisorption for the range of metal oxides $\left(\mathrm{TiO}_{2}, \mathrm{SiO}_{2}, \mathrm{Fe}_{2} \mathrm{O}_{3}\right)$, metallic surfaces $(\mathrm{Au}, \mathrm{Ag})$, organic NPs (CNT, carbon black, graphene), nanodots (CdSe) and can be accessed through NanoCommons Knowledge Base ${ }^{104}$. The presented multiscale methodology can be further extended to evaluate adsorption energies at various $\mathrm{pH}$ regimes and salt concentrations, which will broaden its applicability for the pharmaceutical and food industries.

\section{Supporting Information.}

The file contains additional tables and figures references in the main text of the article (PDF)

\section{Corresponding Author.}

*yulia.subbotina@ucd.ie

\section{Acknowledgements.}

This work was supported by SFI 16/IA/4506 "Quantitative Modelling of Bionano Interface”. The authors also wish to acknowledge the Irish Centre for High-End Computing (ICHEC) and the 
ResearchIT Sonic cluster, which was funded by UCD IT Services and the Research Office, for the provision of computational facilities and support. Julia Subbotina would like personally to thank her parents, Galina and Igor Ovechkin (Miass, Russia), for endless emotional and financial support during her life journey as a STEM researcher.

\section{References}

(1) Maillard, J.-Y.; Hartemann, P. Silver as an Antimicrobial: Facts and Gaps in Knowledge.

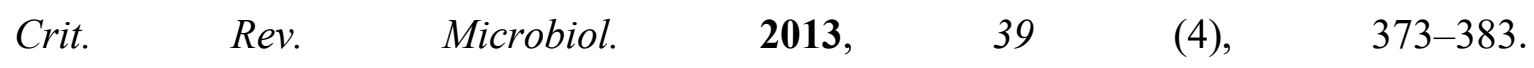
https://doi.org/10.3109/1040841X.2012.713323.

(2) Sim, W.; Barnard, R. T.; Blaskovich, M. A. T.; Ziora, Z. M. Antimicrobial Silver in Medicinal and Consumer Applications: A Patent Review of the Past Decade (2007-2017). Antibiotics. MDPI AG December 1, 2018. https://doi.org/10.3390/antibiotics7040093.

(3) Varner K. E., El-Badawy A., Feldhake D., V. R. State-Of-The-Science Review: Everything NanoSilver and More; 2010.

(4) Azharuddin, M.; Zhu, G. H.; Das, D.; Ozgur, E.; Uzun, L.; Turner, A. P. F.; Patra, H. K. A Repertoire of Biomedical Applications of Noble Metal Nanoparticles. Chem. Commun. 2019, 55 (49), 6964-6996. https://doi.org/10.1039/c9cc01741k.

(5) Malekzad, H.; Sahandi Zangabad, P.; Mirshekari, H.; Karimi, M.; Hamblin, M. R. Noble Metal Nanoparticles in Biosensors: Recent Studies and Applications. Nanotechnology Reviews. Walter de Gruyter GmbH June 27, 2017, pp 301-329. https://doi.org/10.1515/ntrev-2016-0014.

(6) Loiseau, A.; Asila, V.; Boitel-Aullen, G.; Lam, M.; Salmain, M.; Boujday, S. Silver-Based 
Plasmonic Nanoparticles for and Their Use in Biosensing. Biosensors. MDPI AG June 1, 2019. https://doi.org/10.3390/bios9020078.

(7) Doria, G.; Conde, J.; Veigas, B.; Giestas, L.; Almeida, C.; Assunção, M.; Rosa, J.; Baptista, P. V. Noble Metal Nanoparticles for Biosensing Applications. Sensors 2012, 12 (2), 16571687. https://doi.org/10.3390/s120201657.

(8) Rezvani, E.; Rafferty, A.; McGuinness, C.; Kennedy, J. Adverse Effects of Nanosilver on Human Health and the Environment. Acta Biomaterialia. Acta Materialia Inc August 1, 2019, pp 145-159. https://doi.org/10.1016/j.actbio.2019.05.042.

(9) Jonathan H. Shannahan; Ramakrishna Podila; Abdullah A. Aldossari; Hilary Emerson; Brian A. Powell; Pu Chun Ke; Apparao M. Rao; Jared M. Brown. Formation of a Protein Corona on Silver Nanoparticles Mediates Cellular Toxicity via Scavenger Receptors . Toxicol. Sci. 2014, 122 (1), 1-6. https://doi.org/10.1093/TOXSCI.

(10) Nel, A.; Xia, T.; Mädler, L.; Li, N. Toxic Potential of Materials at the Nanolevel. Science. American Association for the Advancement of Science February 3, 2006, pp 622-627. https://doi.org/10.1126/science.1114397.

(11) Ferdous, Z.; Nemmar, A. Health Impact of Silver Nanoparticles: A Review of the Biodistribution and Toxicity Following Various Routes of Exposure. International Journal of Molecular Sciences. MDPI AG April 1, 2020. https://doi.org/10.3390/ijms21072375.

(12) Mahmoudi, M.; Bertrand, N.; Zope, H.; Farokhzad, O. C. Emerging Understanding of the Protein Corona at the Nano-Bio Interfaces. Nano Today 2016, 11 (6), 817-832. https://doi.org/10.1016/J.NANTOD.2016.10.005. 
(13) Monopoli, M. P.; Åberg, C.; Salvati, A.; Dawson, K. A. Biomolecular Coronas Provide the Biological Identity of Nanosized Materials. Nat. Nanotechnol. 2012, 7 (12), 779-786. https://doi.org/10.1038/nnano.2012.207.

(14) Mydin, R. B. S. M. N.; Rahman, W. N.; Lazim, R. M.; Mohd Gazzali, A.; Azlan, N. H. M.; Moshawih, S. Targeted Therapeutic Nanoparticles for Cancer and Other Human Diseases. In Nanotechnology: Applications in Energy, Drug and Food; Springer International Publishing, 2019; pp 187-207. https://doi.org/10.1007/978-3-319-99602-8_8.

(15) Zola, H.; Swart, B.; Banham, A.; Barry, S.; Beare, A.; Bensussan, A.; Boumsell, L.; D. Buckley, C.; Bühring, H. J.; Clark, G.; et al. CD Molecules 2006 - Human Cell Differentiation Molecules. J. Immunol. Methods 2007, 319 (1-2), 1-5. https://doi.org/10.1016/j.jim.2006.11.001.

(16) Beare, A.; Stockinger, H.; Zola, H.; Nicholson, I. Monoclonal Antibodies to Human Cell Surface Antigens. Current protocols in immunology / edited by John E. Coligan ... [et al.]. Wiley-Blackwell 2008, p A.4A.1. https://doi.org/10.1002/0471142735.ima04as80.

(17) Trigueros, S. Nanoscale Metal Particles as Nanocarriers in Targeted Drug Delivery System. J. Nanomedicine Res. 2016, 4 (2). https://doi.org/10.15406/jnmr.2016.04.00086.

(18) Mathur, P.; Jha, S.; Ramteke, S.; Jain, N. K. Pharmaceutical Aspects of Silver Nanoparticles. Artif. Cells, Nanomedicine, Biotechnol. 2018, 46 (sup1), 115-126. https://doi.org/10.1080/21691401.2017.1414825.

(19) Tonigold, M.; Simon, J.; Estupiñán, D.; Kokkinopoulou, M.; Reinholz, J.; Kintzel, U.; Kaltbeitzel, A.; Renz, P.; Domogalla, M. P.; Steinbrink, K.; et al. Pre-Adsorption of 
Antibodies Enables Targeting of Nanocarriers despite a Biomolecular Corona. Nat. Nanotechnol. 2018, 13 (9), 862-869. https://doi.org/10.1038/s41565-018-0171-6.

(20) SMART - Servier Medical ART https://smart.servier.com/ (accessed Nov 11, 2021).

(21) Pagadala, N. S.; Syed, K.; Tuszynski, J. Software for Molecular Docking: A Review. Biophys. Rev. 201792 2017, 9 (2), 91-102. https://doi.org/10.1007/S12551-016-0247-1.

(22) Śledź, P.; Caflisch, A. Protein Structure-Based Drug Design: From Docking to Molecular Dynamics. Curr. Opin. Struct. Biol. 2018, 48, 93-102. https://doi.org/10.1016/J.SBI.2017.10.010.

(23) Cournia, Z.; Allen, B.; Sherman, W. Relative Binding Free Energy Calculations in Drug Discovery: Recent Advances and Practical Considerations. Journal of Chemical Information and Modeling. American Chemical Society December 26, 2017, pp 29112937. https://doi.org/10.1021/acs.jcim.7b00564.

(24) Lazim, R.; Suh, D.; Choi, S. Advances in Molecular Dynamics Simulations and Enhanced Sampling Methods for the Study of Protein Systems. International journal of molecular sciences. NLM (Medline) September 1, 2020. https://doi.org/10.3390/ijms21176339.

(25) Wang, L.; Wu, Y.; Deng, Y.; Kim, B.; Pierce, L.; Krilov, G.; Lupyan, D.; Robinson, S.; Dahlgren, M. K.; Greenwood, J.; et al. Accurate and Reliable Prediction of Relative Ligand Binding Potency in Prospective Drug Discovery by Way of a Modern Free-Energy Calculation Protocol and Force Field. J. Am. Chem. Soc. 2015, 137 (7), 2695-2703. https://doi.org/10.1021/ja512751q.

(26) Cavalli, A.; Spitaleri, A.; Saladino, G.; Gervasio, F. L. Investigating Drug-Target 
Association and Dissociation Mechanisms Using Metadynamics-Based Algorithms. Accounts of Chemical Research. American Chemical Society February 17, 2015, pp 277285. https://doi.org/10.1021/ar500356n.

(27) Chodera, J. D.; Mobley, D. L.; Shirts, M. R.; Dixon, R. W.; Branson, K.; Pande, V. S. Alchemical Free Energy Methods for Drug Discovery: Progress and Challenges. Current Opinion in Structural Biology. Elsevier Current Trends April 1, 2011, pp 150-160. https://doi.org/10.1016/j.sbi.2011.01.011.

(28) Mobley, D. L.; Gilson, M. K. Predicting Binding Free Energies: Frontiers and Benchmarks. Annu. Rev. Biophys. 2017, 46 (1), 531-558. https://doi.org/10.1146/annurev-biophys070816-033654.

(29) Power, D.; Rouse, I.; Poggio, S.; Brandt, E.; Lopez, H.; Lyubartsev, A.; Lobaskin, V. A Multiscale Model of Protein Adsorption on a Nanoparticle Surface. Model. Simul. Mater. Sci. Eng. 2019, 27 (8), 084003. https://doi.org/10.1088/1361-651X/ab3b6e.

(30) Lopez, H.; Lobaskin, V. Coarse-Grained Model of Adsorption of Blood Plasma Proteins onto Nanoparticles. J. Chem. Phys. 2015, 143 (24), 243138. https://doi.org/10.1063/1.4936908.

(31) Lopez, H.; Brandt, E. G.; Mirzoev, A.; Zhurkin, D.; Lyubartsev, A.; Lobaskin, V. Multiscale Modelling of Bionano Interface. In Advances in Experimental Medicine and Biology; Springer, Cham, 2017; Vol. 947, pp 173-206. https://doi.org/10.1007/978-3-319-47754$1 \_7$.

(32) Alsharif, S. A.; Power, D.; Rouse, I.; Lobaskin, V. In Silico Prediction of Protein Adsorption 
Energy on Titanium Dioxide and Gold Nanoparticles. Nanomater. 2020, Vol. 10, Page 1967 2020, 10 (10), 1967. https://doi.org/10.3390/nano10101967.

(33) Rouse, I.; Power, D.; Brandt, E. G.; Schneemilch, M.; Kotsis, K.; Quirke, N.; Lyubartsev, A. P.; Lobaskin, V. First Principles Characterisation of Bio-Nano Interface. Phys. Chem. Chem. Phys. 2021.

(34) Hamaker, H. C. The London-van Der Waals Attraction between Spherical Particles. Physica 1937, 4 (10), 1058-1072. https://doi.org/10.1016/S0031-8914(37)80203-7.

(35) Brandt, E. G.; Lyubartsev, A. P. Molecular Dynamics Simulations of Adsorption of Amino Acid Side Chain Analogues and a Titanium Binding Peptide on the TiO2 (100) Surface. $J$. Phys. Chem. C 2015, 119 (32), 18126-18139. https://doi.org/10.1021/acs.jpcc.5b02670.

(36) Kokh, D. B.; Corni, S.; Winn, P. J.; Hoefling, M.; Gottschalk, K. E.; Wade, R. C. ProMetCS: An Atomistic Force Field for Modeling Protein-Metal Surface Interactions in a Continuum Aqueous Solvent. J. Chem. Theory Comput. 2010, 6 (5), 1753-1768. https://doi.org/10.1021/ct100086j.

(37) Mobley, D.; Gilson, M. Predicting Binding Free Energies: Frontiers and Benchmarks. bioRxiv 2016, 074625. https://doi.org/10.1101/074625.

(38) Christ, C. D.; Mark, A. E.; van Gunsteren, W. F. Basic Ingredients of Free Energy Calculations: A Review. J. Comput. Chem. 2009, 31 (8), NA-NA. https://doi.org/10.1002/jcc.21450.

(39) Ytreberg, F. M.; Swendsen, R. H.; Zuckerman, D. M. Comparison of Free Energy Methods for Molecular Systems. J. Chem. Phys. 2006, 125 (18). https://doi.org/10.1063/1.2378907. 
(40) Shirts, M. R.; Mobley, D. L. An Introduction to Best Practices in Free Energy Calculations; Humana Press, Totowa, NJ, 2013; pp 271-311. https://doi.org/10.1007/978-1-62703-017$5+11$.

(41) Barducci, A.; Bussi, G.; Parrinello, M. Well-Tempered Metadynamics: A Smoothly Converging and Tunable Free-Energy Method. Phys. Rev. Lett. 2008, 100 (2), 020603. https://doi.org/10.1103/PhysRevLett.100.020603.

(42) Abraham, M. J.; Murtola, T.; Schulz, R.; Páll, S.; Smith, J. C.; Hess, B.; Lindahl, E. GROMACS: High Performance Molecular Simulations through Multi-Level Parallelism from Laptops to Supercomputers. SoftwareX 2015, 1-2, 19-25. https://doi.org/10.1016/J.SOFTX.2015.06.001.

(43) Jo, S.; Kim, T.; Iyer, V. G.; Im, W. CHARMM-GUI: A Web-Based Graphical User Interface for CHARMM. J. Comput. Chem. 2008, 29 (11), 1859-1865. https://doi.org/10.1002/jcc.20945.

(44) Bonomi, M.; Branduardi, D.; Bussi, G.; Camilloni, C.; Provasi, D.; Raiteri, P.; Donadio, D.; Marinelli, F.; Pietrucci, F.; Broglia, R. A.; et al. PLUMED: A Portable Plugin for FreeEnergy Calculations with Molecular Dynamics. Comput. Phys. Commun. 2009, 180 (10), 1961-1972. https://doi.org/10.1016/j.cpc.2009.05.011.

(45) Trapl, D.; Spiwok, V. Analysis of the Results of Metadynamics Simulations by Metadynminer and Metadynminer3d.

(46) Schneemilch, M.; Quirke, N. Free Energy of Adhesion of Lipid Bilayers on Silica Surfaces. J. Chem. Phys. 2018, 148 (19), 194704. https://doi.org/10.1063/1.5028557. 
(47) Comer, J.; Tam, K. Lipophilicity Profiles: Theory and Measurement. In Pharmacokinetic Optimization in Drug Research; Verlag Helvetica Chimica Acta: Zürich, 2007; pp 275-304. https://doi.org/10.1002/9783906390437.ch17.

(48) Martin, Y. C. Quantitative Drug Design: A Critical Introduction, Second Edition; CRC Press, 2010.

(49) Hansch, C.; Quinlan, J. E.; Lawrence, G. L. The Linear Free-Energy Relationship between Partition Coefficients and the Aqueous Solubility of Organic Liquids. J. Org. Chem. 1968, 33 (1), 347-350. https://doi.org/10.1021/jo01265a071.

(50) Bannan, C. C.; Calabró, G.; Kyu, D. Y.; Mobley, D. L. Calculating Partition Coefficients of Small Molecules in Octanol/Water and Cyclohexane/Water. J. Chem. Theory Comput. 2016, 12 (8), 4015-4024. https://doi.org/10.1021/acs.jctc.6b00449.

(51) Hughes, Z. E.; Wright, L. B.; Walsh, T. R. Biomolecular Adsorption at Aqueous Silver Interfaces: First-Principles Calculations, Polarizable Force-Field Simulations, and Comparisons with Gold. Langmuir 2013, 29 (43), 13217-13229. https://doi.org/10.1021/la402839q.

(52) Wright, L. B.; Rodger, P. M.; Corni, S.; Walsh, T. R. GolP-CHARMM: First-Principles Based Force Fields for the Interaction of Proteins with $\mathrm{Au}(111)$ and $\mathrm{Au}(100) . \mathrm{J}$. Chem. Theory Comput. 2013, 9 (3), 1616-1630. https://doi.org/10.1021/ct301018m.

(53) Hoefling, M.; Iori, F.; Corni, S.; Gottschalk, K.-E. Interaction of Amino Acids with the $\mathrm{Au}(111)$ Surface: Adsorption Free Energies from Molecular Dynamics Simulations. Langmuir 2010, 26 (11), 8347-8351. https://doi.org/10.1021/la904765u. 
(54) Toman, R. Coxiella Burnetii : Recent Advances and New Perspectives in Research of the $Q$ Fever Bacterium; Springer, 2012.

(55) Geada, I. L.; Ramezani-Dakhel, H.; Jamil, T.; Sulpizi, M.; Heinz, H. Insight into Induced Charges at Metal Surfaces and Biointerfaces Using a Polarizable Lennard-Jones Potential. Nat. Commun. 2018, 9 (1), 716. https://doi.org/10.1038/s41467-018-03137-8.

(56) Raffaini, G.; Ganazzoli, F. Protein Adsorption on Biomaterial and Nanomaterial Surfaces: A Molecular Modeling Approach to Study Non-Covalent Interactions. J. Appl. Biomater. Biomech. 2010, 8 (3), 135-145. https://doi.org/10.5301/JABB.2010.6093.

(57) Heinz, H.; Ramezani-Dakhel, H. Simulations of Inorganic-Bioorganic Interfaces to Discover New Materials: Insights, Comparisons to Experiment, Challenges, and Opportunities. Chem. Soc. Rev. 2016, 45 (2), 412-448. https://doi.org/10.1039/c5cs00890e.

(58) Huang, J.; Rauscher, S.; Nawrocki, G.; Ran, T.; Feig, M.; De Groot, B. L.; Grubmüller, H.; MacKerell, A. D. CHARMM36m: An Improved Force Field for Folded and Intrinsically Disordered Proteins. Nat. Methods 2016, $14 \quad$ (1), 71-73. https://doi.org/10.1038/nmeth.4067.

(59) Martin, L.; Bilek, M. M.; Weiss, A. S.; Kuyucak, S. Force Fields for Simulating the Interaction of Surfaces with Biological Molecules. Interface Focus 2016, 6 (1), 20150045. https://doi.org/10.1098/rsfs.2015.0045.

(60) Heinz, H.; Jha, K. C.; Luettmer-Strathmann, J.; Farmer, B. L.; Naik, R. R. Polarization at Metal-Biomolecular Interfaces in Solution. J. R. Soc. Interface 2011, 8 (55), 220-232. https://doi.org/10.1098/rsif.2010.0318. 
(61) Kohlmeyer, A.; Vermaas, J.; Braun, E. Akohlmey/Topotools: Release 1.8. 2020. https://doi.org/10.5281/ZENODO.3845031.

(62) Jo, S.; Cheng, X.; Islam, S. M.; Huang, L.; Rui, H.; Zhu, A.; Lee, H. S.; Qi, Y.; Han, W.; Vanommeslaeghe, K; ; et al. CHARMM-GUI PDB Manipulator for Advanced Modeling and Simulations of Proteins Containing Nonstandard Residues. In Advances in Protein Chemistry and Structural Biology; Academic Press Inc., 2014; Vol. 96, pp 235-265. https://doi.org/10.1016/bs.apcsb.2014.06.002.

(63) Herne, T. M.; Ahern, A.; Garrell, R. L. Surface-Enhanced Raman Spectroscopy of Peptides: Preferential N-Terminal Adsorption on Colloidal Silver. J. Am. Chem. Soc. 1991, 113 (3), 846-854. https://doi.org/10.1021/ja00003a018.

(64) Sinha-Roy, R.; García-González, P.; Weissker, H. C. How Metallic Are Noble-Metal Clusters? Static Screening and Polarizability in Quantum-Sized Silver and Gold Nanoparticles. Nanoscale 2020, 12 (7), 4452-4458. https://doi.org/10.1039/c9nr08608k.

(65) Martinez, C. R.; Iverson, B. L. Rethinking the Term "Pi-Stacking." Chemical Science. Royal Society of Chemistry June 6, 2012, pp 2191-2201. https://doi.org/10.1039/c2sc20045g.

(66) Dakal, T. C.; Kumar, A.; Majumdar, R. S.; Yadav, V. Mechanistic Basis of Antimicrobial Actions of Silver Nanoparticles. Front. Microbiol. 2016, 7 (NOV), 1831. https://doi.org/10.3389/fmicb.2016.01831.

(67) Banerjee, N.; Mukhopadhyay, S. Viral Glycoproteins: Biological Role and Application in Diagnosis. VirusDisease. Springer India March 1, 2016, pp 1-11. 
https://doi.org/10.1007/s13337-015-0293-5.

(68) Misra, S.; Sharma, V.; Srivastava, A. K. Bacterial Polysaccharides: An Overview. In Polysaccharides: Bioactivity and Biotechnology; Springer International Publishing, 2015; pp 81-108. https://doi.org/10.1007/978-3-319-16298-0_68.

(69) Zobel, M.; Neder, R. B.; Kimber, S. A. J. Universal Solvent Restructuring Induced by Colloidal Nanoparticles. Science (80-. $\quad$ ). $\quad \mathbf{2 0 1 5}, 347$ (6219), 292-294. https://doi.org/10.1126/science.1261412.

(70) Cataliotti, R. S.; Aliotta, F.; Ponterio, R. Silver Nanoparticles Behave as Hydrophobic Solutes towards the Liquid Water Structure in the Interaction Shell. A Raman Study in the O-H Stretching Region. Phys. Chem. Chem. Phys. 2009, 11 (47), 11258-11263. https://doi.org/10.1039/b915317a.

(71) Xiao, Y.; Wiesner, M. R. Characterization of Surface Hydrophobicity of Engineered Nanoparticles. J. Hazard. Mater. 2012, 215-216, 146-151. https://doi.org/10.1016/j.jhazmat.2012.02.043.

(72) Desmet, C.; Valsesia, A.; Oddo, A.; Ceccone, G.; Spampinato, V.; Rossi, F.; Colpo, P. Characterisation of Nanomaterial Hydrophobicity Using Engineered Surfaces. $J$. Nanoparticle Res. 2017, 19 (3), 1-17. https://doi.org/10.1007/s11051-017-3804-z.

(73) Valsesia, A.; Desmet, C.; Ojea-Jiménez, I.; Oddo, A.; Capomaccio, R.; Rossi, F.; Colpo, P. Direct Quantification of Nanoparticle Surface Hydrophobicity. Commun. Chem. 2018, 1 (1), 1-11. https://doi.org/10.1038/s42004-018-0054-7.

(74) Weston, J. S.; Jentoft, R. E.; Grady, B. P.; Resasco, D. E.; Harwell, J. H. Silica Nanoparticle 
Wettability: Characterization and Effects on the Emulsion Properties. Ind. Eng. Chem. Res. 2015, 54 (16), 4274-4284. https://doi.org/10.1021/ie504311p.

(75) He, L.-B.; Zhang, L.; Tan, X.-D.; Tang, L.-P.; Xu, T.; Zhou, Y.-L.; Ren, Z.-Y.; Wang, Y.; Teng, C.-Y.; Sun, L.-T.; et al. Surface Energy and Surface Stability of Ag Nanocrystals at Elevated Temperatures and Their Dominance in Sublimation-Induced Shape Evolution. Small 2017, 13 (27), 1700743. https://doi.org/10.1002/smll.201700743.

(76) Mehl, M. J.; Papaconstantopoulos, D. A. Applications of a Tight-Binding Total-Energy Method for Transition and Noble Metals: Elastic Constants, Vacancies, and Surfaces of Monatomic Metals. Phys. Rev. B - Condens. Matter Mater. Phys. 1996, 54 (7), 4519-4530. https://doi.org/10.1103/PhysRevB.54.4519.

(77) mp-124: Ag (cubic, Fm-3m, 225) https://materialsproject.org/materials/mp-124/ (accessed Aug 12, 2020).

(78) Polsterová, S.; Friák, M.; Všianská, M.; Šob, M. Quantum-Mechanical Assessment of the Energetics of Silver Decahedron Nanoparticles. Nanomaterials 2020, 10 (4). https://doi.org/10.3390/nano10040767.

(79) Iosin, M.; Canpean, V.; Astilean, S. Spectroscopic Studies on PH- and Thermally Induced Conformational Changes of Bovine Serum Albumin Adsorbed onto Gold Nanoparticles. $J$. Photochem. Photobiol. A Chem. 2011, 217 (2-3), 395-401.

(80) Ravindran, A.; Singh, A.; Raichur, A. M.; Chandrasekaran, N.; Mukherjee, A. Studies on Interaction of Colloidal Ag Nanoparticles with Bovine Serum Albumin (BSA). Colloids Surfaces B Biointerfaces 2010, 76 (1), 32-37. 
(81) Gebregeorgis, A.; Bhan, C.; Wilson, O.; Raghavan, D. Characterization of Silver/Bovine Serum Albumin (Ag/BSA) Nanoparticles Structure: Morphological, Compositional, and Interaction Studies. J. Colloid Interface Sci. 2013, 389 (1), 31-41. https://doi.org/10.1016/j.jcis.2012.08.041.

(82) Siddiq, A. M.; Murugan, D.; Srivastava, R.; Alam, M. S. Influence of PH on Interaction of Silver Nanoparticles - Protein: Analyses by Spectroscopic and Thermodynamic Ideology. $\begin{array}{llllll}\text { Colloids } \quad \text { Surfaces } \quad B \quad \text { Biointerfaces } & \mathbf{2 0 1 9}, & 184, & 110524 .\end{array}$ https://doi.org/10.1016/j.colsurfb.2019.110524.

(83) Bhunia, A. K.; Kamilya, T.; Saha, S. Silver Nanoparticle-Human Hemoglobin Interface: Time Evolution of the Corona Formation and Interaction Phenomenon. Nano Converg. 2017, 4 (1), 28. https://doi.org/10.1186/s40580-017-0122-1.

(84) Zolghadri, S.; Saboury, A. A.; Golestani, A.; Divsalar, A.; Rezaei-Zarchi, S.; MoosaviMovahedi, A. A. Interaction between Silver Nanoparticle and Bovine Hemoglobin at Different Temperatures. J. Nanoparticle Res. 2009, 11 (7), 1751-1758. https://doi.org/10.1007/s11051-008-9538-1.

(85) Li, X.; Yang, Z.; Peng, Y. The Interaction of Silver Nanoparticles with Papain and Bromelain. New J. Chem. 2018, 42 (7), 4940-4950. https://doi.org/10.1039/c7nj04847e.

(86) Wang, G.; Hou, H.; Wang, S.; Yan, C.; Liu, Y. Exploring the Interaction of Silver Nanoparticles with Lysozyme: Binding Behaviors and Kinetics. Colloids Surfaces B Biointerfaces 2017, 157, 138-145. https://doi.org/10.1016/j.colsurfb.2017.05.071.

(87) Xu, X.; Wang, Y.; Wang, H.; Su, H.; Mao, X.; Jiang, L.; Liu, M.; Sun, D.; Hou, S. Synthesis 
of Triangular Silver Nanoprisms and Studies on the Interactions with Human Serum Albumin. J. Mol. Liq. 2016, 220, 14-20. https://doi.org/10.1016/j.molliq.2016.02.103.

(88) Maji, A.; Beg, M.; Mandal, A. K.; Das, S.; Jha, P. K.; Hossain, M. Study of the Interaction of Human Serum Albumin with Alstonia Scholaris Leaf Extract-Mediated Silver Nanoparticles Having Bactericidal Property. Process Biochem. 2017, 60, 59-66. https://doi.org/10.1016/j.procbio.2017.05.022.

(89) Das, A.; Chakrabarti, A.; Das, P. K. Probing Protein Adsorption on a Nanoparticle Surface Using Second Harmonic Light Scattering. Phys. Chem. Chem. Phys. 2016, 18 (35), 2432524331. https://doi.org/10.1039/c6cp02196d.

(90) Nayak, P. S.; Borah, S. M.; Gogoi, H.; Asthana, S.; Bhatnagar, R.; Jha, A. N.; Jha, S. Lactoferrin Adsorption onto Silver Nanoparticle Interface: Implications of Corona on Protein Conformation, Nanoparticle Cytotoxicity and the Formulation Adjuvanticity. Chem. Eng. J. 2019, 361, 470-484. https://doi.org/10.1016/j.cej.2018.12.084.

(91) Wang, G.; Lu, Y.; Hou, H.; Liu, Y. Probing the Binding Behavior and Kinetics of Silver Nanoparticles with Bovine Serum Albumin. RSC Adv. 2017, 7 (15), 9393-9401. https://doi.org/10.1039/C6RA26089F.

(92) Helmlinger, J.; Sengstock, C.; Groß-Heitfeld, C.; Mayer, C.; Schildhauer, T. A.; Köller, M.; Epple, M. Silver Nanoparticles with Different Size and Shape: Equal Cytotoxicity, but Different Antibacterial Effects. $R S C \quad A d v . \quad$ 2016, $6 \quad$ (22), 18490-18501. https://doi.org/10.1039/C5RA27836H.

(93) Saeb, A. T. M.; Alshammari, A. S.; Al-Brahim, H.; Al-Rubeaan, K. A. Production of Silver 
Nanoparticles with Strong and Stable Antimicrobial Activity against Highly Pathogenic and Multidrug Resistant Bacteria. Sci. World J. 2014, 2014, 1-9. https://doi.org/10.1155/2014/704708.

(94) Faria, M.; Björnmalm, M.; Thurecht, K. J.; Kent, S. J.; Parton, R. G.; Kavallaris, M.; Johnston, A. P. R.; Gooding, J. J.; Corrie, S. R.; Boyd, B. J.; et al. Minimum Information Reporting in Bio-Nano Experimental Literature. Nat. Nanotechnol. 2018139 2018, 13 (9), 777-785. https://doi.org/10.1038/s41565-018-0246-4.

(95) Penna, M. J.; Mijajlovic, M.; Biggs, M. J. Molecular-Level Understanding of Protein Adsorption at the Interface between Water and a Strongly Interacting Uncharged Solid Surface. J. Am. Chem. Soc. 2014, 136 (14), 5323-5331. https://doi.org/10.1021/ja411796e.

(96) Roach, P.; Farrar, D.; Perry, C. C. Interpretation of Protein Adsorption: Surface-Induced Conformational Changes. J. Am. Chem. Soc. 2005, 127 (22), 8168-8173. https://doi.org/10.1021/ja042898o.

(97) Mijajlovic, M.; Penna, M. J.; Biggs, M. J. Free Energy of Adsorption for a Peptide at a Liquid/Solid Interface via Nonequilibrium Molecular Dynamics. Langmuir 2013, 29 (9), 2919-2926. https://doi.org/10.1021/la3047966.

(98) Hartvig, R. A.; Van De Weert, M.; Østergaard, J.; Jorgensen, L.; Jensen, H. Protein Adsorption at Charged Surfaces: The Role of Electrostatic Interactions and Interfacial Charge Regulation. Langmuir 2011, 27 (6), 2634-2643. https://doi.org/10.1021/la104720n.

(99) Petersen, B.; Roa, R.; Dzubiella, J.; Kanduč, M. Ionic Structure around Polarizable Metal Nanoparticles in Aqueous Electrolytes. Soft Matter 2018, 14 (20), 4053-4063. 
https://doi.org/10.1039/c8sm00399h.

(100) Zhdanov, V. P.; Kasemo, B. Van Der Waals Interaction during Protein Adsorption on a Solid Covered by a Thin Film. Langmuir 2001, 17 (18), 5407-5410. https://doi.org/10.1021/LA0104222.

(101) Liu, R.; Jiang, W.; Walkey, C. D.; Chan, W. C. W.; Cohen, Y. Prediction of NanoparticlesCell Association Based on Corona Proteins and Physicochemical Properties. Nanoscale 2015, 7 (21), 9664-9675. https://doi.org/10.1039/c5nr01537e.

(102) Kamath, P.; Fernandez, A.; Giralt, F.; Rallo, R. Predicting Cell Association of SurfaceModified Nanoparticles Using Protein Corona Structure - Activity Relationships (PCSAR). Curr. Top. Med. Chem. 2015, $15 \quad$ (18), 1930-1937. https://doi.org/10.2174/1568026615666150506152808.

(103) Bitbucket https://bitbucket.org/softmattergroup/ (accessed Dec 11, 2020).

(104) NanoCommons - Nano-Knowledge Community https://www.nanocommons.eu/ (accessed Jan 15, 2021). 